\title{
ALCALÓIDES ALQUILPIRIDÍNICOS DE ESPONJAS MARINHAS
}

\author{
Adaíla M. P. Almeida, Roberto G. S. Berlinck* \\ Instituto de Química de São Carlos - Universidade de São Paulo - CP 780 - 13560-970 - São Carlos - SP \\ Eduardo Hajdu \\ Departamento de Zoologia - Instituto de Biociências - Universidade de São Paulo - CP 11294 - 05422-970 - São Paulo - SP
}

Recebido em 8/3/96; aceito em 29/8/96

\begin{abstract}
ALKYLPYRIDINE ALKALOIDS FROM MARINE SPONGES. The chemistry of alkylpyridine alkaloids originating from marine sponges is comprehensively reviewed, with emphasis on their natural occurrence, methods for their isolation, spectroscopic characterization, biological activities e chemical synthesis. A likely chemotaxonomic role is suggested, as markers for sponges of the Order Haplosclerida (Demospongiae).
\end{abstract}

Keywords: marine sponges; alkylpyridine alkaloids.

\section{INTRODUÇÃO}

Esponjas (Phylum Porifera) são animais aquáticos, marinhos ou de água doce, sésseis na fase adulta, de cores, formas e dimensões variadas. São metazoários primitivos (considera-se que as esponjas surgiram há entre 600.000.000 e 450.000.000 anos, no período Cambriano), provavelmente os primeiros animais pluricelulares a surgirem ao longo da evolução. As esponjas não possuem órgãos ou sistemas diferenciados, suas células não constituem tecidos strictu sensu, e as ligações intercelulares são lábeis e instáveis. Devido a seu caráter primitivo, as esponjas são um dos elementos dominantes em diversos ecossistemas marinhos passados e presentes, dentre estes os arrecifes coralinos e os ambientes antárticos ${ }^{1-3}$.

Mais de 5000 espécies de esponjas já foram descritas até o momento presente. O filo Porifera é cosmopolita, podendo ser encontrado da faixa entremarés ao assoalho dos oceanos, inclusive em fossas abissais (abaixo de 8000 metros). A classificação atual dos espongiários divide o filo Porifera em dois subfilos: Symplasma com uma única Classe, Hexactinellida (esponjas com esqueleto formado por espículas com seis pontas, ou hexáctinas, compostas de silício), também conhecidas como esponjas-de-vidro; e Cellularia, com duas Classes, Calcarea (esponjas com esqueleto formado por espículas de carbonato de cálcio), e Demospongiae (esponjas com esqueleto de espículas de silício ou de espongina, ou ainda de uma combinação de ambas), esta compreendendo $90 \%$ do número total de espécies $^{4-9}$. Apesar de estudados há mais de um século e meio, ainda há questões fundamentais a responder acerca dos Porifera devido, em grande parte, à controvérsias quanto à sua taxonomia, o acesso à muitas espécies só ter sido possível após o advento do mergulho autônomo a partir da II Guerra Mundial, bem como à dificuldade de sua manutenção em aquários devido a sua morte precoce ou significativas alterações no seu padrão metabólico. Dentre os invertebrados, os espongiários são os menos estudados do ponto de vista biológico ${ }^{10}$.

Considera-se que as esponjas foram os primeiros animais marinhos estudados do ponto de vista químico ${ }^{11-16}$. Estudos com produtos naturais de esponjas marinhas forneceram importantes informações do ponto de vista quimiotaxonômico ${ }^{17-20}$, ecológico $^{19-38}$, e sobre sua química e bioquímica ${ }^{1,38-43}$. Porém, tendose em vista que diversas espécies de esponjas apresentam associações com cianobactérias e bactérias ${ }^{44-47}$, considera-se que vários produtos naturais isolados de esponjas possam ser originários de microorganismos ${ }^{48}$.

A toxicidade dos Porifera tem sido constatada desde a antiguidade. Em 200 a.C. o poeta grego Oppian relatou o trabalho de mergulhadores do Mediterrâneo que coletavam esponjas para sua utilização medicinal e cosmética ${ }^{49}$ :

"He [the diver] then makes for the rocks and discovers the sponges he is seeking. They [the sponges] grow on the underwater rocks and they seem to be part of the submerged reefs [...]. Without losing a moment, he darts at the sponges, vigoroulsy wielding his knife, which is something like a sickle. As soon as he has severed the sponge from the rock, he pulls the cord to let his companions above know that he must now be pulled to the surface as quikly as possible. Once cut away from the rock, the sponge bleeds a nauseating liquid which spreads around the diver and is sometimes sufficient to kill him, so offensive is the smell to the nostrils of man. That is the reason why the diver is eager to depart, and now his companions draw him up to the surface as rapidly as possible."*

A toxicidade de extratos de esponjas foi bem documentada em diversos programas de triagem de atividades biológicas, demonstrando suas atividades citotóxicas, ictiotóxicas, antibacterianas, antifúngicas, neurotóxicas, e tóxicas de uma forma geral $^{50-61}$. Como consequência, nos últimos 30 anos centenas de compostos foram isolados de esponjas marinhas, mostrando que estas possuem um metabolismo secundário extremamente diversificado e que muitas das substâncias isoladas apresentam potentes atividades biológicas e farmacológicas ${ }^{62-65}$.

Esta revisão tem por objetivo discutir o isolamento e a caracterização espectroscópica de alcalóides alquilpiridínicos isolados de esponjas marinhas. Ainda que esta classe de compostos não seja a mais representativa do filo Porifera, poucos compostos desta natureza foram isolados de outras fontes naturais ${ }^{66,67,76}$ (como, por exemplo, moluscos ${ }^{66-72}$, microorganis$\operatorname{mos}^{73}$ e vertebrados ${ }^{74,75}$ ). Além disso, alcalóides alquilpiridínicos isolados de esponjas marinhas têm ocorrência restrita e

\footnotetext{
* "Ele [o mergulhador] vai às pedras e descobre a esponja que procura. Elas [as esponjas] crescem em rochas subaquáticas e parecem ser parte dos arrecifes submersos [...]. Sem perder tempo, ele as corta vigorosamente com uma pequena foice. Tão logo arranca a esponja da rocha, ele puxa a corda à qual está atado chamando seus companheiros para ser levado para a superfície. Uma vez arrancada da rocha, a esponja sangra um líquido nauseante que se espalha ao redor do mergulhador e é por vezes suficiente para matá-lo, tão ofensivo é seu cheiro para as narinas do homem. É por esta razão que o mergulhador está ansioso para partir, e agora seus companheiros o trazem para a superfície tão rápido quanto possível." (tradução dos autores).
} 
provavelmente uma origem biogenética comum, podendo eventualmente ser utilizados como marcadores quimiotaxonômicos. Aqui também são discutidas as rotas sintéticas desenvolvidas para a obtenção destes compostos, bem como as atividades biológicas e farmacológicas dos compostos em questão. Além disso, propomos uma rota de biossíntese para alcalóides alquilpiridínicos isolados de esponjas marinhas baseada na proposta originalmente sugerida para alcalóides do tipo manzamina.

\section{OCORRÊNCIA, ISOLAMENTO, DETERMINAÇÃO ESTRUTURAL E ATIVIDADES BIOLÓGICAS}

Em 1978, Schmitz e colaboradores ${ }^{77,78}$ isolaram a halitoxina (1) da esponja Amphimedon compressa (originalmente como Haliclona rubens). Os extratos n-butanólico e aquoso desta esponja apresentaram pronunciada citotoxicidade (em células da linhagem KB), ação hemolítica e toxicidade aguda para camundongos. Estes extratos foram submetidos à ultra-filtração em diferentes membranas de retenção de compostos de massa molecular na faixa de 500-1000, 1000-25000 e maior que 25000 unidades de massa atômica, fornecendo frações idênticas por $\mathrm{RMN}-{ }^{1} \mathrm{H}$. O principal componente destas frações era a halitoxina (1). Este composto foi também purificado por cristalização de seu sal de picrato, o qual foi posteriormente convertido em cloridrato, bem como por cromatografia em diferentes resinas de troca iônica, cromatografia em adsorventes inorgânicos, por filtração em gel, cromatografia em polipropileno, em celulose $10 \%$ acetilada, além de outros métodos. De todos, a ultra-filtração em membranas mostrou ser o mais eficiente. Os produtos obtidos após purificação por todas estas técnicas apresentaram idênticos espectros de $\mathrm{RMN}-{ }^{1} \mathrm{H}$ e as mesmas atividades biológicas.

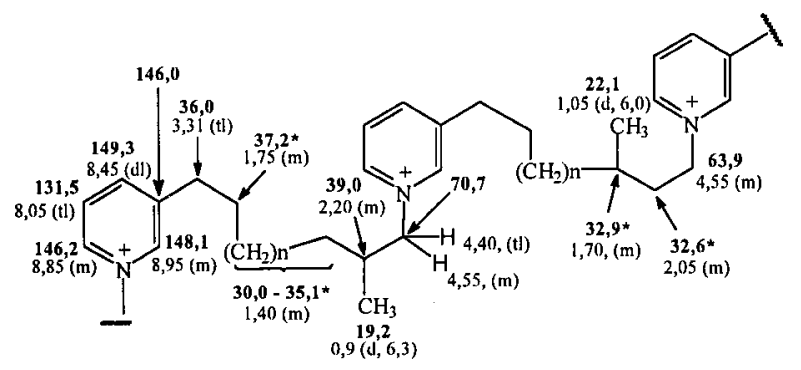

A análise por combustão indicou uma fórmula empírica $\mathrm{C}_{15} \mathrm{H}_{24} \mathrm{NCl} .2 \mathrm{H}_{2} \mathrm{O}$, com porcentagens variáveis de enxôfre e fósforo, os quais foram considerados como sendo impurezas do tipo íons sulfato e fosfato. O espectro de ultravioleta apresentou bandas características de um sal de alquilpiridínio $\left(\lambda_{\max }\right.$ 267,273 e $212 \mathrm{~nm}$ ), fato confirmado pelas análises por infravermelho (banda em $1640 \mathrm{~cm}^{-1}$ ) e $\mathrm{RMN}-{ }^{1} \mathrm{H}$. Este último espectro, descrito por Schmitz et al. ${ }^{77}$, mostra sinais típicos de um grupo $N$-alquilpiridínio 3 -alquil substituído, o qual apresenta quatro diferentes deslocamentos químicos: os dois mais desblindados $(\delta \sim 9,0)$ se referem aos hidrogênios ligados aos carbonos vizinhos ao nitrogênio quaternizado; o sinal aromático intermediário $(\delta \sim 8,5)$ se refere ao hidrogênio em posição para com relação ao nitrogênio quaternizado, e o sinal aromático mais blindado $(\delta \sim 8,0)$ se refere ao próton presente na posição 5. Schmitz e colaboradores atribuíram os sinais de RMN- ${ }^{1} \mathrm{H}$ da halitoxina (1) tanto por comparação com compostos modelo, como por experiências de desacoplamento seletivo a 100 e $360 \mathrm{MHz}$. Além disso, os autores observaram nestes espectros a presença de um dublete em 1,05 ppm, com aproximadamente $1 / 3$ da intensidade do dublete em 0,92 ppm. Assim, sugeriram a presença de duas diferentes cadeias alquila na estrutura da halitoxina: uma com um radical metila em posição $\beta$ com relação ao nitrogênio quaternizado, e outra em posição $\gamma$ com relação ao nitrogênio quaternizado. Esta hipótese foi confirmada por degradação química: o aquecimento da halitoxina (1) a $140-160^{\circ} \mathrm{C}$ decompôs o composto, fornecendo uma mistura de 3-alquenilpiridinas e de 3-( $\omega$-cloroalquil)piridinas. Os produtos da pirólise foram analisados por cromatografia gasosa acoplada à espectrometria de massas, bem como por RMN- ${ }^{1} \mathrm{H}$ e espectrometria de massas após separação dos produtos por cromatografia gasosa em escala preparativa. A análise dos dados obtidos confirmou a presença de duas diferentes cadeias ligadas ao anel piridínico. Devido à ausência de dados espectroscópicos que indicassem a presença de qualquer grupo metila terminal ou de anéis piridínicos não quaternizados, os autores propuseram uma estrutura cíclica para a halitoxina.

Apesar de fornecer os dados de $\mathrm{RMN}-{ }^{13} \mathrm{C}$, os autores somente atribuíram os sinais dos carbonos ligados aos nitrogênios quaternizados nas duas diferentes cadeias alquila. Além disso, sugeriram que, como a maior parte do material isolado constitui a fração com massa molecular na faixa de 500 a 1000 unidades de massa atômica, a estrutura do componente majoritário da mistura deve conter de 4 a 6 unidades alquilpiridínicas, com uma distribuição aleatória dos dois diferentes tipos de cadeia alquila.

Com o objetivo de estudar a ocorrência da halitoxina em esponjas de espécies taxonomicamente próximas, Schmitz et al. ${ }^{77,78}$ extraíram outras esponjas do gênero Amphimedon e Haliclona e analisaram seus extratos hidroalcoólicos por RMN${ }^{1} \mathrm{H}$ bem como pelos testes de citotoxicidade e de ação hemolítica. As esponjas Amphimedon viridis (originalmente Haliclona viridis), Amphimedon erina (originalmente Haliclona erina), Haliclona sp. e Haliclona permalis mostraram composições variáveis de halitoxina, fato observado principalmente pelas diferenças de atividade citotóxica dos extratos destas esponjas nos testes acima mencionados.

Recentemente, iniciamos um programa de screening e isolamento de substâncias bioativas de esponjas marinhas ${ }^{79,80}$. De dez espécies de esponjas coletadas, extraídas e testadas em testes de atividade citotóxica e hemolítica, os extratos nbutanólico e aquoso de Amphimedon viridis mostraram ser os mais ativos. O subsequente fracionamento do extrato nbutanólico desta esponja em Sephadex LH-20 levou ao isolamento da halitoxina (1). O espectro de $\mathrm{RMN}-{ }^{1} \mathrm{H}$ da halitoxina por nós isolada de $A$. viridis ${ }^{81}$ é idêntico àquele apresentado por Schmitz et al. ${ }^{77,78}$. A análise espectroscópica da halitoxina (1) de A. viridis por diferentes técnicas de ressonância magnética nuclear (COSY ${ }^{1} \mathrm{H}-{ }^{1} \mathrm{H}$, HETCOR ${ }^{1} \mathrm{H}_{-}{ }^{13} \mathrm{C}$ ) confirmou as atribuições feitas por Schmitz por desacoplamento seletivo, bem como possibilitou a atribuição dos sinais de carbono 13 da halitoxina $(\mathbf{1})^{81}$. Além disso, os espectros de $\mathrm{RMN}-{ }^{1} \mathrm{H}$ da halitoxina isolada de Amphimedon compressa ${ }^{77,78}$ e de A. viridis ${ }^{81}$ indicam sinais de impurezas em $3,7 \mathrm{ppm}$ e na região entre 5.0 e $5.5 \mathrm{ppm}$, os quais provavelmente se referem à presença da amphitoxina (43, recentemente isolada de A. compressa ${ }^{96}$; ver abaixo) em ambas amostras.

No que se refere à composição da halitoxina por nós isolada de A. viridis, realizamos medidas de massa molecular por cromatografia de permeação em gel de alto desempenho (HPGPC), as quais indicaram três picos de massa molecular de aproximadamente 500, 2000 e 5000 unidades de massa atômica. Assim, a composição da mistura de halitoxina presente em A. viridis difere daquela originária de Haliclona rubens (A. compressa) no que se refere ao peso molecular de seus componentes. Em termos estruturais, esta parece ser a única diferença entre as duas amostras de origem distinta. Testes realizados com a halitoxina de $A$. viridis mostraram suas potentes atividades hemolítica $\left(\mathrm{LD}_{50} 2,2 \pm 0,5 \mathrm{ng}\right)$, citotóxica, e neurotóxica ${ }^{81}$. Porém, ainda não se conhece o mecanismo de ação deste composto a nível de membranas, tanto no que se refere à formação 
de poros em membranas de hemácias como em membranas neurais. No momento, estudos farmacológicos estão sendo realizados para melhor se compreender o mecanismo de ação da halitoxina ${ }^{82}$.

Quase dez anos após o isolamento da halitoxina por Schmitz e colaboradores, Quiñoà e Crews $^{83}$ isolaram as nifatinas da esponja Niphates sp. O extrato metanólico da esponja foi particionado com hexano, $\mathrm{CCl}_{4}$ e $\mathrm{CH}_{2} \mathrm{Cl}_{2}$, e as duas últimas frações foram reunidas e purificadas por cromatografia de fase reversa e HPLC, fornecendo a nifatina A (2) e a nifatina B (3), esta última contaminada com a nifatina A. A determinação estrutural dos dois compostos foi realizada por análises espectroscópicas (espectrometria de massas por impacto eletrônico de alta resolução, $\mathrm{RMN}-{ }^{1} \mathrm{H}$ e $-{ }^{13} \mathrm{C}$ ), bem como por comparação com os valores de $\mathrm{RMN}-{ }^{1} \mathrm{H}$ e ${ }^{-13} \mathrm{C}$ estabelecidos para o 1 hexino. A única diferença entre a nifatina $\mathrm{A}(\mathbf{2})$ e a nifatina $\mathrm{B}$ (3) é a posição da ligação tripla na cadeia alifática ligada ao anel piridínico. Apesar de os autores atribuírem o sinal de $\mathrm{RMN}-{ }^{1} \mathrm{H}$ entre 1,2 e $1,5 \mathrm{ppm}$ a nove grupos metileno, somente oito destes grupos da nifatina A são passíveis de absorverem nesta região. A nifatina $\mathrm{A}$ (2) mostrou atividade citotóxica em células da linhagem P388 a uma dose de $\mathrm{IC}_{50}=0,5 \mu \mathrm{g} / \mathrm{mL}$.

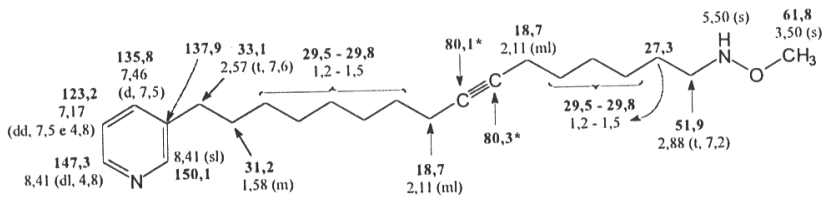

(2) nifatina $\left.\mathrm{A}(\mathrm{RMN}-1 \mathrm{H}, 300 \mathrm{MHz} ; \mathrm{RMN}\lrcorner 3 \mathrm{C}, 75 \mathrm{MHz} \mathrm{cm} \mathrm{CDCl}{ }_{3}\right)$

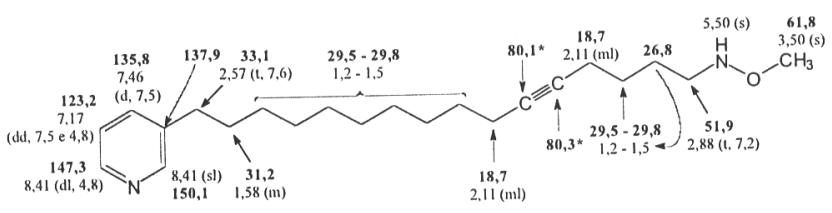

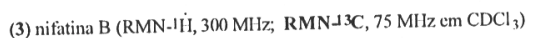

Kobayashi e colaboradores ${ }^{84}$ isolaram as teoneladinas A (4), B (5), C (6) e D (7) da esponja Theonella swinhoei por cromatografia em silica-gel, seguido de purificação por HPLC. Os compostos foram identificados pela análise de suas propriedades espectroscópicas, principalmente espectrometria de massas por impacto de elétrons e por técnicas de ressonância magnética nuclear mono- e bi-dimensionais, porém somente os dados espectroscópicos da teoneladina B (5) foram apresentados e discutidos detalhadamente. É de se notar que os autores assinalam composição elementar destoante com os valores de massa exata medidos para as teoneladinas A (4) e B (5): no caso do primeiro composto, os autores indicam a fórmula $\mathrm{C}_{20} \mathrm{H}_{32} \mathrm{~N}_{2}$ para uma massa exata de $\mathrm{m} / \mathrm{z} 289.2575$ do íon quase-molecular $[\mathrm{M}+1]^{+}$(por espectrometria de massas de alta resolução de bombardeamento rápido de átomos), e no caso do segundo os autores indicam a fórmula $\mathrm{C}_{21} \mathrm{H}_{34} \mathrm{~N}_{2}$ para uma massa exata de $\mathrm{m} / \mathrm{z} 303.2766$ do íon quase-molecular $[\mathrm{M}+1]^{+}$. Em ambos os casos, observa-se que as fórmulas corretas correspondem àquelas que possuem um átomo de carbono a menos. Os autores atribuem uma multiplicidade do tipo quarteto para o sinal do próton aromático em $\delta 7,34$, bem como para o próton em $\delta 2,38$, quando, na realidade, deveria se designar, para o primeiro caso uma multiplicidade do tipo duplo dubleto, e para o segundo uma multiplicidade do tipo duplo tripleto. Os autores destacam as diferenças espectroscópicas entre os derivados $N$-metilados (teoneladinas B (5) e D (7)) e seus respectivos derivados demetilados (teoneladinas A (4) e C (6)) como sendo: a) o deslocamento químico do carbono em posição $\alpha$ ao mesmo nitrogênio, e; b) o padrão de fragmentação em espectrometria de massas por impacto eletrônico. Os autores ainda observaram a presença de análogos ramificados com grupos metila das teoneladinas $\mathrm{C}$ e $\mathrm{D}$, os quais não foram separados por HPLC. Os compostos isolados possuem potentes atividades antineoplásticas in vitro em linfomas $\mathrm{L} 1210$ [ $\mathrm{IC}_{50}=4,7$ $\mu \mathrm{g} / \mathrm{mL}$ (4), 1,0 $\mu \mathrm{g} / \mathrm{mL}$ (5), 3,6 $\mu \mathrm{g} / \mathrm{mL}(\mathbf{6})$ e $1,6 \mu \mathrm{g} / \mathrm{mL}$ (7) ] e em células de carcinoma da epiderme $\mathrm{KB}\left[\mathrm{IC}_{50}=4,7 \mu \mathrm{g} / \mathrm{mL}\right.$ (4), $1,0 \mu \mathrm{g} / \mathrm{mL}$ (5), 3,6 $\mu \mathrm{g} / \mathrm{mL}$ (6) e $1,6 \mu \mathrm{g} / \mathrm{mL}$ (7) ]. Estes compostos também possuem potente atividade estimuladora da liberação de $\mathrm{Ca}^{2+}$ em retículo sarcoplasmático ${ }^{85}$.

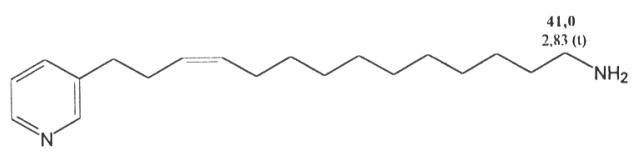

(4) teoncladina $\Lambda$ (RMN- $\left.1 / \mathrm{CD}_{3} \mathrm{OD} ; \mathrm{RMN}-13 \mathrm{C} \mathrm{CDCl}_{3}\right)$

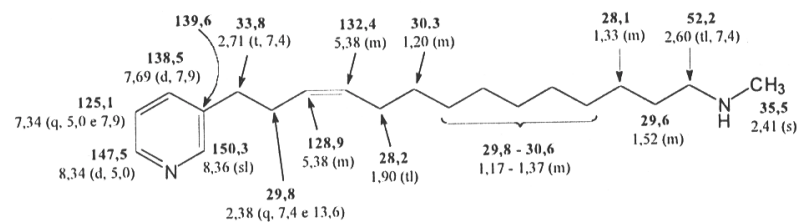

(5) teoncladina $\mathrm{B}\left(\mathrm{RMN}-{ }^{1} \mathrm{HCD} \mathrm{CD}_{3} \mathrm{OD} ; \mathrm{RMN}^{-13} \mathrm{C} \mathrm{CDCl}_{3}\right)$

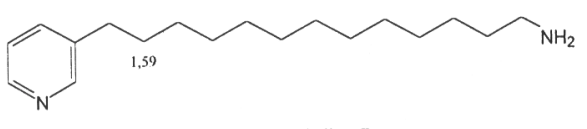

(6) teoncladina C

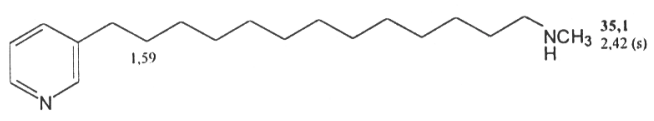

(7) teoneladina $\mathrm{D}$ ( $\mathrm{RMN}-1 \mathrm{H} \mathrm{CD}_{3} \mathrm{OD} ; \mathrm{RMN}^{-13} \mathrm{C} \mathrm{CDCl}_{3}$ )

Carroll e Scheuer ${ }^{86}$ isolaram quatro alcalóides $\beta$-alquilpiridínicos de uma esponja marinha não identificada. $O$ extrato clorofórmico desta esponja apresentou atividade citotóxica em células da linhagem KB. O isolamento e purificação das ikiminas A (8), B (10), C (12) e D (13), e de dois artefatos, syn-ikimina A (9) e syn-ikimina B (11), foram realizados por cromatografia líquida à vácuo em silica-gel, seguido por HPLC em fase normal (sílica-gel) e em fase normal aminada. A ikimina $\mathrm{A}(\mathbf{8})$ foi isolada em mistura com a syn-ikimina $\mathrm{A}(\mathbf{9})$, o mesmo acontecendo com a ikimina B (10) e a syn-ikimina B (11). As estruturas de todos os compostos foram elucidadas pela análise de seus dados espectroscópicos, principalmente por $\mathrm{RMN}-{ }^{1} \mathrm{H}$ (incluíndo experiências de desacoplamento homonuclear), RMN $-{ }^{13} \mathrm{C}$ e espectrometria de massas por impacto eletrônico. A estereoquímica anti-, atribuída à ligação dupla do tipo imina dos produtos originalmente presentes nos extratos, foi estabelecida com base nos valores de deslocamento químico dos hidrogênios da imina, bem como do metileno adjacente no caso da ikimina A (8), e confirmada por experiências de n.O.e. Os autores verificaram que a presença dos isômeros syndas ikiminas A (8) e B (10) é devido ao fato destes sofrerem isomerização quando em solução em $\mathrm{CHCl}_{3}$, obtendo misturas 
na proporção de 3:1 anti/syn, caracterizando os isômeros syn como artefatos de isolamento. As únicas atribuições questionáveis apresentadas pelos autores são os valores das integrações das metilas na posição 17 da ikimina $\mathrm{A}(\mathbf{8})$ e da syn-ikimina A (9), às quais é atribuído o valor de 1 hidrogênio. Os compostos isolados apresentaram os seguintes valores de inibição do desenvolvimento celular de células da linhagem $\mathrm{KB}\left(\mathrm{IC}_{50} \mathrm{em} \mu \mathrm{g} / \mathrm{mL}\right)$ : ikimina $\mathrm{A}(\mathbf{8})=5$; ikimina $\mathrm{B}(\mathbf{1 0})=7$; ikimina $\mathrm{C}(\mathbf{1 2})=5$.

Matsunaga e colaboradores ${ }^{87}$ isolaram os óxidos das cribrochalinaminas da esponja Cribrochalina sp. A fração etérea do extrato etanólico da referida esponja foi submetido à

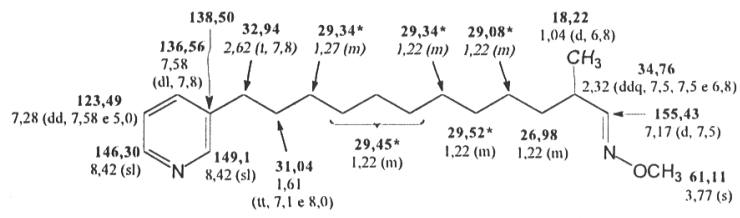

(8) ikimina A (RMN-1 $11300 \mathrm{MHz} ; \mathrm{RMN}^{-3} \mathrm{C} 75 \mathrm{MHz}, \mathrm{CDCl}_{3}$ )

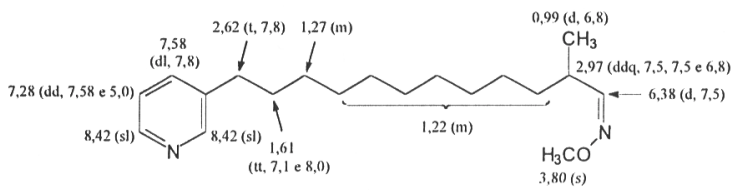

(9) $s y n$-ikimina $\Lambda\left(\mathrm{RMN}^{-1} \mathrm{H} 300 \mathrm{MHz}, \mathrm{CDCl}_{3}\right)$

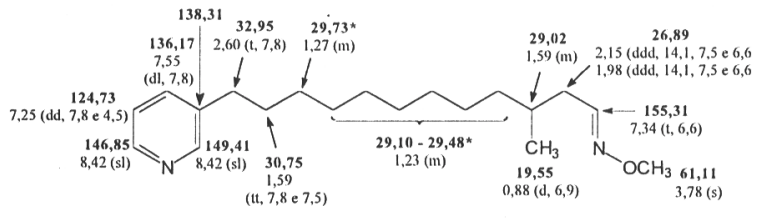

(10) ikimina B (RMN-I $\left.\left.{ }^{\mathrm{H}} 300\right) \mathrm{MHz}, \quad \mathrm{RMN}{ }^{\perp 3} \mathrm{C} 75 \mathrm{MHz}_{3} \mathrm{CDCl}_{3}\right)$

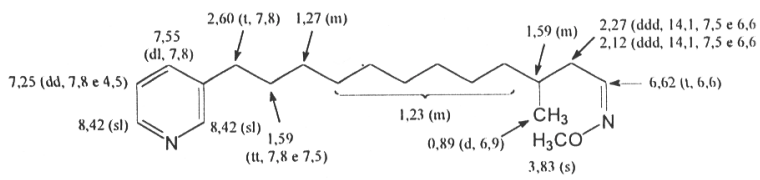

(11) s.yn-ikimina $\mathrm{B}\left(\mathrm{RMN}-1 \mathrm{H} 300 \mathrm{MHz}, \mathrm{CDCl}_{3}\right)$

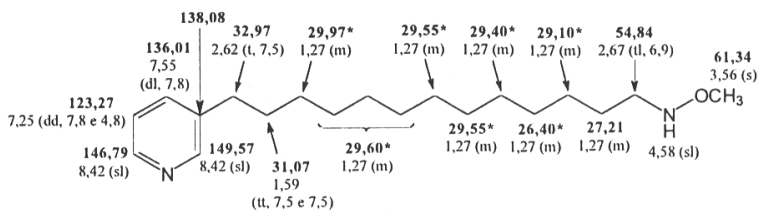

(12) ikimina C (RMN-1 11300$) \mathrm{MHz}$; RMN-13 $\mathrm{C}^{2} 5 \mathrm{MHz}, \mathrm{CDCl}_{3}$ )

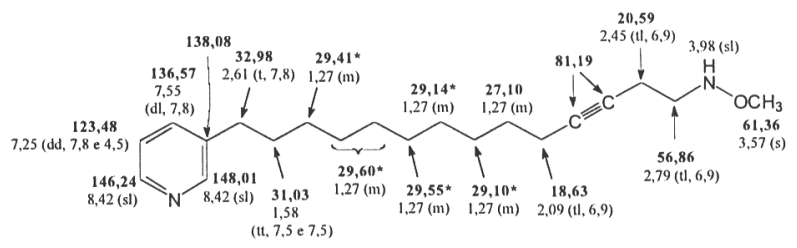

(13) ikimina $\mathrm{D}(\mathrm{RMN}-1 \mathrm{H}$ 3(K) $\mathrm{MHz} ; \mathrm{RMN}\lrcorner 3 \mathrm{C} 75 \mathrm{MHz}, \mathrm{CDCl}_{3}$ ) uma partição entre n-hexano e $\mathrm{MeOH} / \mathrm{H}_{2} \mathrm{O}$ 9:1. A fração metanólico-aquosa foi subsequentemente submetida à separação por cromatografia "relâmpago" em fase reversa, em sílicagel, por HPLC em fase reversa e em sílica-gel aminada, fornecendo o óxido da cribrochalinamina A (14) e o óxido da cribrochalinamina B (15). Suas estruturas foram estabelecidas pela análise de seus dados espectroscópicos, incluíndo espectrometria de massas de alta resolução de bombardeamento rápido de átomos, bem como experiências de ressonância magnética nuclear em uma e em duas dimensões. A presença de um raro grupo funcional, $N$-óxido azometino, foi proposto com base na análise dos dados espectroscópicos dos produtos naturais e por comparação com as propriedades espectroscópicas do modelo sintético (16) preparado pelos autores. Os dados espectroscópicos apresentados no artigo são contraditórios, pois diferentes valores de deslocamento químico e/ou de constantes de acoplamento são indicadas para átomos idênticos. Além disso, os autores atribuíram apenas alguns dos sinais de RMN${ }^{1} \mathrm{H}$ e $\mathrm{RMN}^{-13} \mathrm{C}(\mathrm{C}-18, \mathrm{C}-20, \mathrm{C}-21, \mathrm{C}-22$ e C-23). As outras atribuições indicadas nas fórmulas $(\mathbf{1 4}),(\mathbf{1 5})$ e (16) é por nós sugerida, baseando-se nas atribuições dos dados espectroscópicos dos alcalóides alquilpiridínicos isolados das outras esponjas marinhas aqui apresentados.

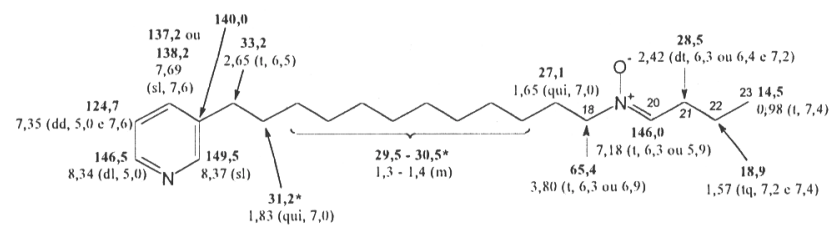

(14) óxido de cribrochalinamina $\Lambda$ (RMN- ${ }^{1} \mathrm{H}$; $\left.\mathrm{RMN}-{ }^{13} \mathrm{C} \mathrm{CD}_{3} \mathrm{OD}\right)$

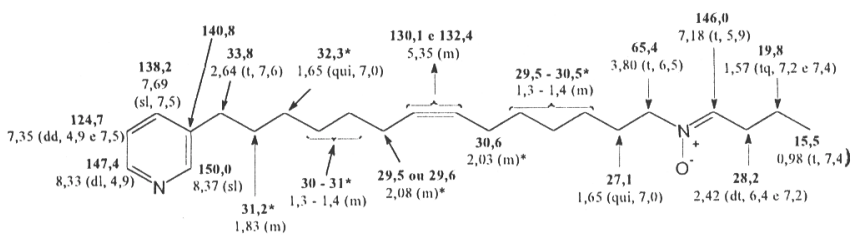

(15) óxido de cribrochalinamina $\mathrm{B}$ ( $\left.\mathrm{RMN}-11 \mathrm{1} ; \mathrm{RMN}-{ }^{13} \mathrm{C} \mathrm{CD}_{3} \mathrm{OD}\right)$

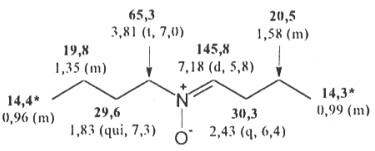

(16)

Duas séries de nifatesinas foram isoladas da esponja Niphates sp. por Kobayashi et al. ${ }^{88}$. O extrato metanólico da esponja foi particionado entre acetato de etila e água. A fração orgânica foi submetida à separações por cromatografia "relâmpago" em sílica-gel, e as frações com atividades antineoplásticas foram purificadas por HPLC em coluna de fase reversa, fornecendo uma primeira série de alcalóides alquilpiridínicos, nifatesinas A-D (17)-(20). As estruturas dos compostos foram elucidadas por análise espectroscópica [UV, FABMS, EIMS, RMN- ${ }^{1} \mathrm{H}, \mathrm{RMN}-{ }^{13} \mathrm{C}$, COSY ${ }^{1} \mathrm{H}^{-1} \mathrm{H}$, HMQC ${ }^{1} \mathrm{H}^{-13} \mathrm{C}$ e HMBC $\left.{ }^{1} \mathrm{H}-{ }^{13} \mathrm{C}\right]$. Porém, algumas atribuições não foram estabelecidas para estes compostos, sendo por nós sugeridas. Por exemplo, o valor de deslocamento químico de ${ }^{13} \mathrm{C}$ para o carbono 2 das nifatesinas B (18), C (19) e D (20) não é indicado, sendo atribuídos dois valores de deslocamento químico de ${ }^{13} \mathrm{C}$ para o carbono 4 destes compostos. Por analogia aos compostos 
precedentes (2) - (16), supomos que o carbono mais desblindado deve ser o carbono 2 (entre o nitrogênio e a cadeia alquila), seguido do carbono 6 e subsequentemente o carbono 4, questionando assim a atribuição dos autores para o carbono 4 do anel piridínico da nifatesina A (17). Deve-se notar o fato de termos atribuído o valor de 39,1 ppm para o carbono 17 e o valor de 37,9 ppm para o carbono 18 da nifatesina $\mathrm{D}(\mathbf{2 0})$ por analogia às atribuições da 3 -metilbutilamina ${ }^{89}$.

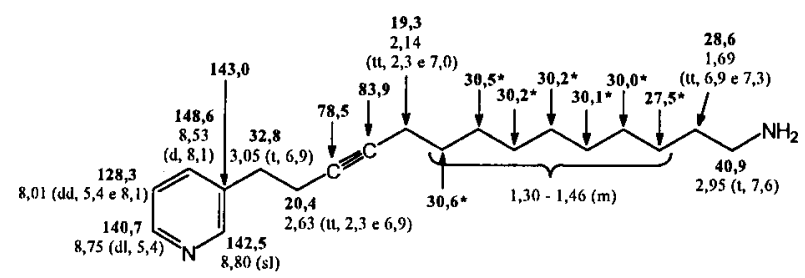

(17): nifatesina $\mathrm{A}\left(\mathrm{RMN}-{ }^{1} \mathrm{H} 500 \mathrm{MHz}\right.$; $\left.\mathrm{RMN}^{-13} \mathrm{C} 125 \mathrm{MHz}, \mathrm{CD}_{3} \mathrm{OD}\right)$

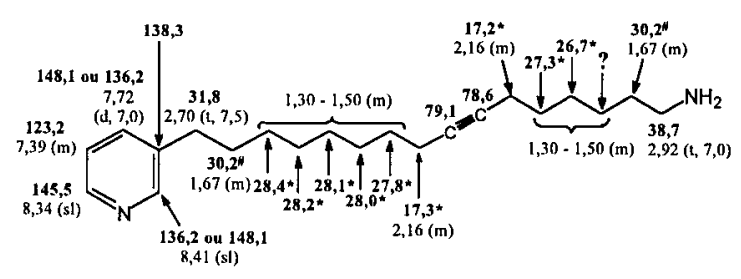

(18): nifatesina B (RMN-1 ${ }^{\mathrm{H}} 500 \mathrm{MHz}$; RMN-13C $\left.125 \mathrm{MHz}, \mathrm{CD}_{3} \mathrm{OD}\right)$

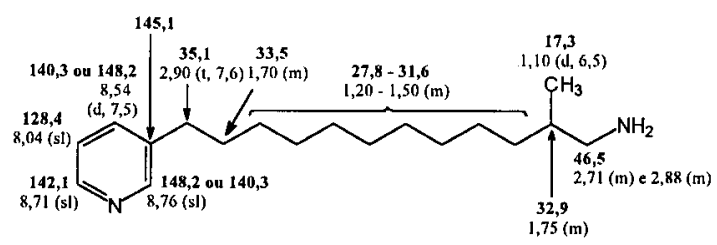

(19): nifatesina C (RMN- ${ }^{-} \mathrm{H} 500 \mathrm{MHz}$; RMN-13C $\left.125 \mathrm{MHz}, \mathrm{CD}_{3} \mathrm{OD}\right)$

A segunda série de nifatesinas E-H (21) - (24), provenientes da mesma esponja ${ }^{90}$, foi igualmente isolada (por cromatografia em sílica-gel e por HPLC em fase reversa) da fração solúvel em acetato de etila proveniente do extrato metanólico. Como para a série anterior, os compostos foram identificados pela análise de suas propriedades espectroscópicas (UV, IV, RMN${ }^{1} \mathrm{H}$ e $\mathrm{RMN}-{ }^{13} \mathrm{C}$ ). Vários sinais de deslocamento químico de ${ }^{1} \mathrm{H}$ e ${ }^{13} \mathrm{C}$ não foram atribuídos para estes compostos. No caso da nifatesina $\mathrm{E}$ (21), o valor de deslocamento químico de ${ }^{13} \mathrm{C}$ de um dos carbonos, presumivelmente C-19 (o metileno adjacente à função metoximina) não é indicado. Dois valores de deslocamento químico de ${ }^{13} \mathrm{C}$ foram observados para $\mathrm{C}-20(\mathrm{CH}=\mathrm{N})$ e $\mathrm{C}-21\left(\mathrm{NOCH}_{3}\right)$ devido à presença dos isômeros $E$ e $Z$ da função metoximina. No que se refere à nifatesina $F(\mathbf{2 2})$, três valores de deslocamento químico não são indicados, os quais supomos ser àqueles referentes aos metilenos C-17 (adjacente à ligação tripla), C-21 (adjacente à função metoximino) e possivelmente um dos metilenos de uma das duas cadeias alifáticas separadas entre si pela ligação tripla. Observa-se novamente dois valores de deslocamento químico de ${ }^{13} \mathrm{C}$ e ${ }^{1} \mathrm{H}$ para o sistema metoximina, referentes aos dois isômeros $E$ e $Z$. A nifatesina G (23) é um homólogo superior da ikimina A (8), e também foi isolada na forma de uma mistura dos dois isômeros syn e anti e identificada por comparação com os dados espectroscópicos do

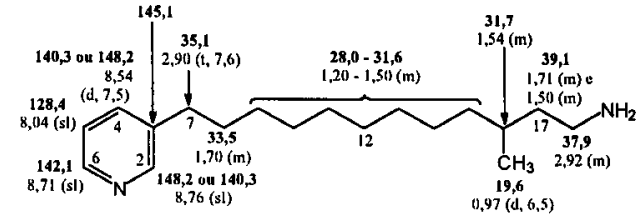

(20): nifatesina D (RMN-1H $500 \mathrm{MHz}$; RMN-13C $125 \mathrm{MHz}, \mathrm{CD}_{3} \mathrm{OD}$ )

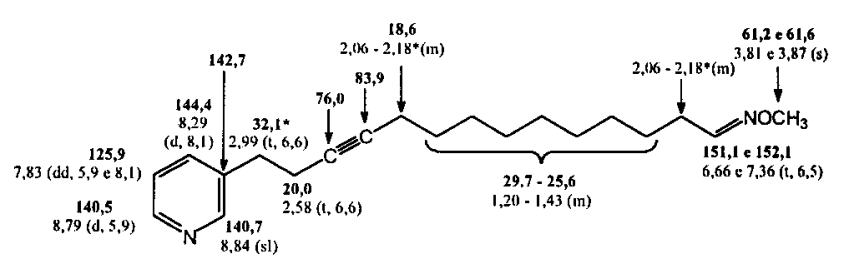

(21): nifatesina $\mathrm{E}\left(\mathrm{RMN}-{ }^{-1} \mathrm{H} ; \mathrm{RMN}-{ }^{13} \mathrm{C} . \mathrm{CDCl}_{3}\right)$

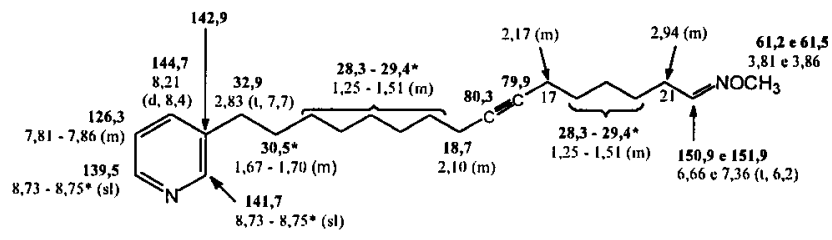

(22): nifatesina $\mathrm{F}$ (RMN-1 $\mathrm{H} 500 \mathrm{MHz} ; \mathrm{RMN}-{ }^{13} \mathrm{C} 125 \mathrm{MHz}, \mathrm{CD}_{3} \mathrm{OD}$ )

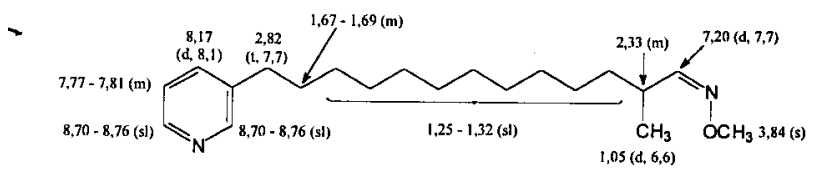

(23): nitatesina $\mathrm{G}\left(\mathrm{RMN} \cdot \mathrm{l}^{\mathrm{H}}, \mathrm{CDCl}_{3}\right)$

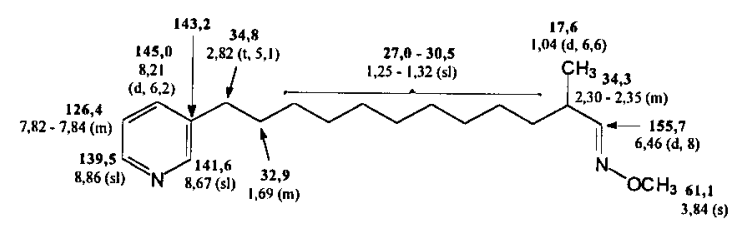

(8) anti-ikimina A (segundo Kobayashi $e f\left(a l^{(x)}\right)$
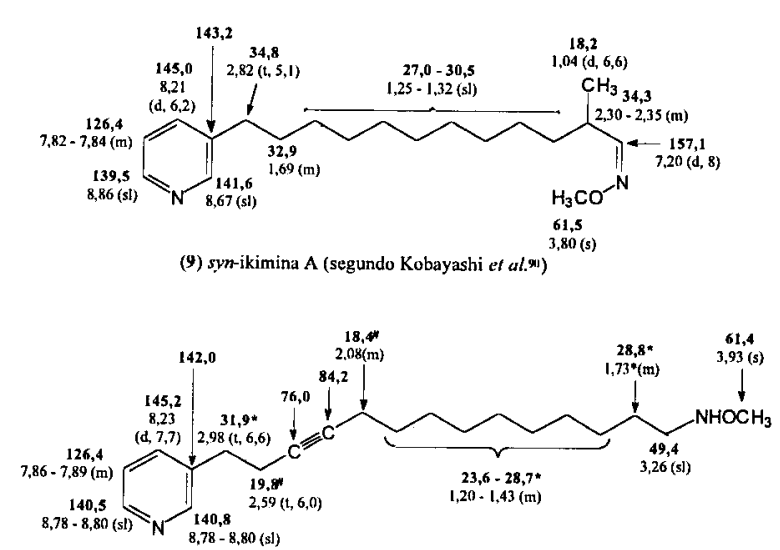

(24): nifatesina $\mathrm{H}\left(\mathrm{RMN}-1 \mathrm{H} ; \mathbf{R M N}-13 \mathrm{C}, \mathrm{CDCl}_{3}\right)$

composto previamente isolado por Carroll e Scheuer ${ }^{86}$. A presença do grupo metoximina na ikimina A (8) isolada por 
Kobayashi et al $^{90}$ foi confirmada pela metanólise em MeOH/ $\mathrm{HCl} 3 \mathrm{M}$ fornecendo o aldeído correspondente. Os autores não indicaram os valores de $\mathrm{RMN}-{ }^{13} \mathrm{C}$ para a nifatesina $\mathrm{G}(\mathbf{2 3})$, mas somente àqueles referentes à anti-ikimina $\mathrm{A}(\mathbf{8})$, e à $s y n$-ikimina A (9). Observa-se que vários valores de deslocamento químico de ${ }^{13} \mathrm{C}$ dos dois isômeros da ikimina A são diferentes daqueles assinalados por Carroll e Scheuer, inclusive as atribuições do anel piridínico. Carroll e Scheuer ${ }^{86}$ atribuem valores decrescentes de deslocamento químico de ${ }^{13} \mathrm{C}$ para os carbonos $2,6,3,4$ e 5 (respectivamente), enquanto que Kobayashi et al..$^{90}$ o fazem para os carbonos 4, 3, 2, 6 e 5 (respectivamente). Acreditamos que as atribuições de Carroll e Scheuer são corretas, visto que a ordem decrescente de deslocamento químico dos carbonos 2,6 , 3 , 4 e 5 segue aquela atribuída para a maioria dos outros alcalóides desta família, como seria de se esperar: os carbonos 2 e 6 estão adjacentes ao heteroátomo; o carbono 3 é quaternário; o carbono 4 se situa em posição para com relação ao heteroátomo, e deve ser desblindado por efeito mesomérico; e o carbono 5 , em posição meta com relação ao heteroátomo, deve ser o menos desblindado de todos os carbonos aromáticos. Finalmente, a nifatesina $\mathrm{H}$ (24) mostrou ser o análogo hidrogenado (na função imina) da nifatesina E (21), pela análise de seus dados espectroscópicos como também por comparação àqueles da nifatina A (2). Kobayashi et al. ${ }^{90}$ atribuem o valor de deslocamento químico de 145,2 ppm para o carbono 4 da nifatesina $\mathrm{H}$ (24); porém, este deve ter sido invertido com a atribuição do carbono 2 (140,8 ppm), via de regra o mais desblindado dos carbonos nesta família de compostos. As nifatesinas E-H (21) (24) apresentaram atividades citotóxicas em células de linfomas L1210 e em células KB de carcinomas humanos da epiderme em doses entre $\mathrm{IC}_{50} 1,9 \mathrm{mg} / \mathrm{cm}^{3}$ e $7,9 \mathrm{mg} / \mathrm{cm}^{3}$.

Também duas séries de xestaminas foram isoladas de duas esponjas diferentes. A primeira série, xestaminas A (25), B (26) e C (27), foi isolada de Xestospongia wiedenmayeri ${ }^{91}$ por cromatografia a contra-corrente centrífuga, seguida de purificação por HPLC. As estruturas destes compostos foram elucidadas por várias técnicas espectroscópicas (UV, IV, RMN${ }^{1} \mathrm{H}, \mathrm{RMN}-{ }^{13} \mathrm{C},{ }^{1} \mathrm{H}-{ }^{1} \mathrm{H}$ COSY e HETCOR ${ }^{1} \mathrm{H}-{ }^{13} \mathrm{C}$ ) bem como pela hidrogenação catalítica da xestamina A (25), seguido da clivagem da ligação $N$-metoxi com zinco em ácido acético, fornecendo a $\mathrm{N}$-metiloctadecanoilpiridina correspondente.

A segunda série de xestaminas, proveniente de Calyx podatypa $^{92}$, compreende as xestaminas D (28), E (29), F (30), G (31) e H (32). As xestaminas A (25) e B (26) também foram isoladas desta mesma esponja. As xestaminas D, E e F foram isoladas da fração orgânica originária da partição do extrato metanólico da esponja entre acetato de etila e água, obtendo-se uma mistura das xestaminas D e E, e separadamente a xestamina $F$. As xestaminas $\mathrm{G}$ e $\mathrm{H}$ também foram isoladas sob forma de mistura, mas a partir da fração aquosa. Os métodos de isolamento utilizados foram a cromatografia de permeação em gel de Sephadex LH-20 e cromatografia à contra-corrente centrífuga. Como para a série anterior, a determinação estrutural das xestaminas D - H (28) - (32) envolveu a utilização de diferentes técnicas espectroscópicas, principalmente a análise por cromatografia em fase gasosa acoplada à espectrometria de massas, que permitiu a análise da mistura de xestaminas $\mathrm{D}$ e E, e das xestaminas $\mathrm{G}$ e H. A estrutura da xestamina $F(30)$ foi determinada por comparação à da xestamina $\mathrm{A}(\mathbf{2 5})$. Esta última foi convertida em xestamina $F(\mathbf{3 0})$ por tratamento com iodeto de metila. Fato interessante, os derivados com nitrogênio quaternizados, xestaminas F (30), G (31) e H (32), apresentaram atividade antimicrobiana 100 vezes mais potentes do que as xestaminas $\mathrm{A}, \mathrm{B}, \mathrm{D}$ e $\mathrm{E}$, o que sugere que a carga positiva no nitrogênio do núcleo piridínico possa ser importante na atividade antimicrobiana observada em Staphylococcus aureus, Bacillus subtilis e Candida albicans.

As nifatoxinas A (33) e B (34) foram isoladas sob forma de uma mistura a partir do extrato diclorometânico da esponja

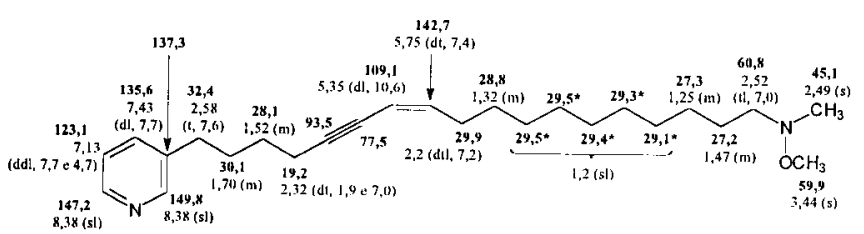

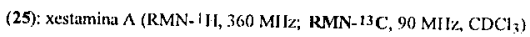

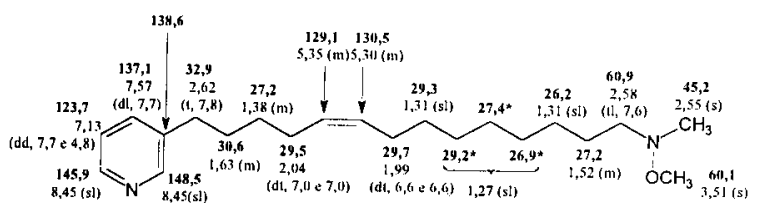

(26): xestamina B (RMN- 111, 360 MIIZ; RMN-13 C, $90 \mathrm{MHz}, \mathrm{CDCl}_{3}$ )

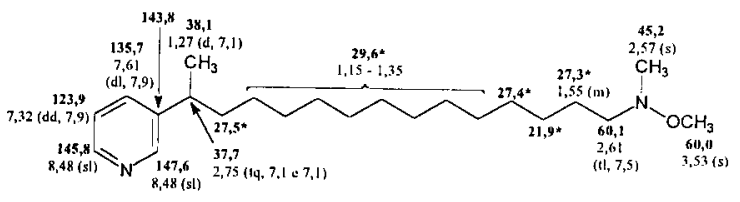

(27): xestamina $\mathrm{C}\left(\mathrm{RMN}-111,360 \mathrm{MIJ} ;, \mathrm{RMN}-{ }^{13} \mathrm{C}, 90 \mathrm{MHz}, \mathrm{CDCl}_{3}\right)$
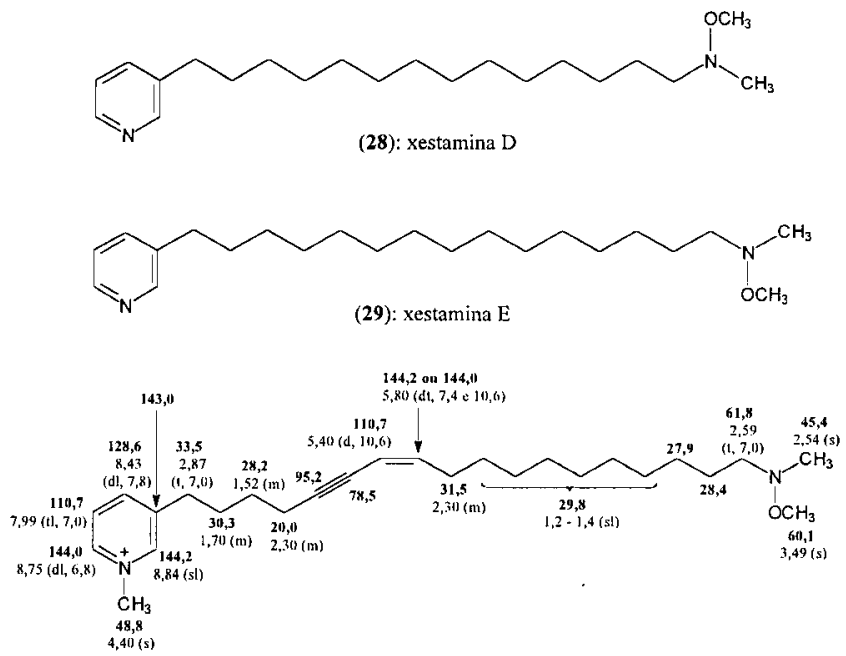

(30): xestamina F (RMN-1H, $360 \mathrm{MHz}$; RMN-13C, $90 \mathrm{MHz}, \mathrm{CDCl}_{3}$ )

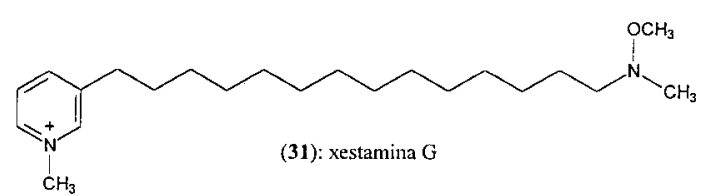

$\mathrm{CH}_{3}$

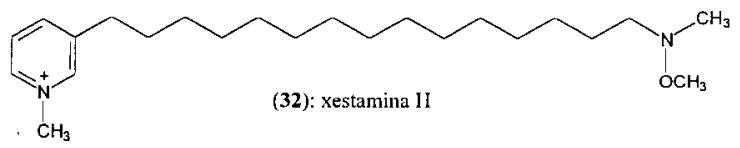

Niphates sp. por uma série de partições com diferentes solventes, seguido por isolamento e purificação em Sephadex LH-20 ${ }^{93}$. As estruturas foram elucidadas pela análise de seus dados espectroscópicos (FABMS, COSY ${ }^{1} \mathrm{H}-{ }^{1} \mathrm{H}, \mathrm{HMQC}{ }^{1} \mathrm{H}-{ }^{13} \mathrm{C}, \mathrm{HMBC}{ }^{1} \mathrm{H}-$ ${ }^{13} \mathrm{C}$, n.O.e. por diferença e TOCSY). Apesar dos autores atribuírem detalhadamente os sinais mais característicos, alguns sinais de ${ }^{13} \mathrm{C}$ e de ${ }^{1} \mathrm{H}$ das cadeias alquila não são sequer mencionados. 


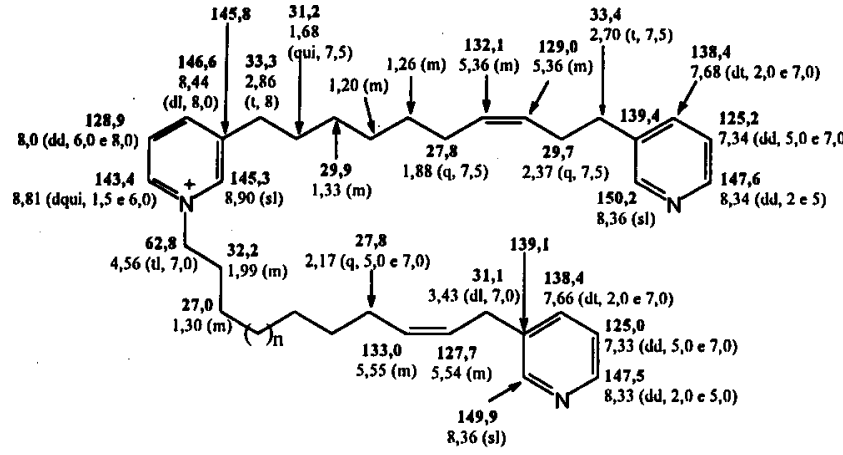

(33) nifatoxina $A(n=2)$ e 34$)$ nifatoxina $B(n=3)$ (RMN-1H $500 \mathrm{MHz}, \mathrm{RMN}^{\perp 3} \mathrm{C} 125 \mathrm{MHz}, \mathrm{CDCl}_{3}$ )

Uma série de alcalóides alquilpiridínicos simétricos foram isolados da esponja Stelletta maxima ${ }^{94}$, as ciclostellettaminas A-F (35)-(40). Os extratos polares desta esponja inibiram a ligação do antagonista seletivo benzilato de metilquinuclidina ao receptor muscarínico da acetilcolina, que é um receptor relacionado aos processos de memória e aprendizagem ${ }^{94}$. $\mathrm{O}$ isolamento dos compostos foi realizado por cromatografia de permeação em gel de Sephadex LH-20, cromatografia em óxido de alumínio e purificação por HPLC de fase reversa, fornecendo os alcalóides (35)-(40) em quantidades abaixo de $1 \mathrm{mg}$. As estruturas das ciclostellettaminas foram elucidadas por análise espectroscópica, principalmente por espectrometria de massas de bombardeamento rápido de átomos.

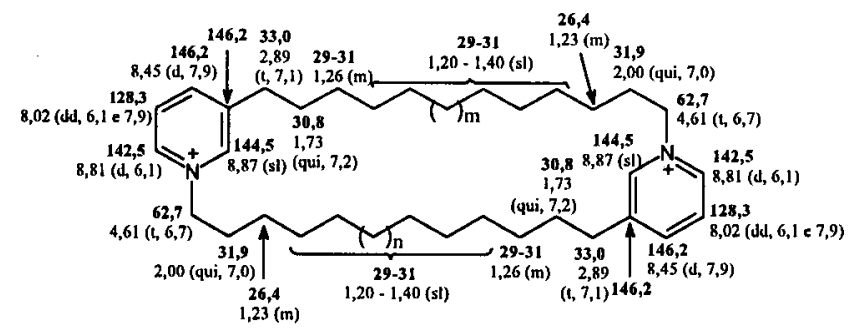

(35): ciclostelletamina A $m=1, n=1$ (RMN- $\left.1 \mathrm{H}, \mathrm{RMN}-13 \mathrm{C} \mathrm{CD} \mathrm{CD}_{3} \mathrm{OD}\right)$ (36): ciciostelletamina $B \mathrm{~m}=1, \mathrm{n}=2$ (37): ciclostelletamina $C m=2, n=2$ (38): ciclostelletamina $D$ m $=1, n=3$ (39): ciclostelletamina $\mathrm{E} m=2, n=3$ (40): ciclostelletamina $F \mathrm{~m}=3, \mathrm{n}=3$

Um polímero denominado "inibidor do receptor do fator de crescimento da epiderme" (inhibitor of the epidermal growth factor receptor), (41) foi isolado da esponja Callyspongia fi$\operatorname{brosa}^{95}$ a partir de seu extrato aquoso. Este foi submetido à cromatografia em Sephadex LH-20, cromatografia centrífuga por contra-corrente gota-à-gota, e purificação por HPLC. Apenas os valores de $\mathrm{RMN}-{ }^{1} \mathrm{H}$ foram atribuídos, porém não os de $\mathrm{RMN}-{ }^{13} \mathrm{C}$. Como no caso da halitoxina, o maior problema foi a determinação do peso molecular de (41). Foram feitas tentativas no sentido de se formar um derivado que não apresentasse carga positiva, como por exemplo pela reação de hidrogenação $\left(\mathrm{H}_{2}, \mathrm{PtO}_{2}, \mathrm{MeOH}\right)$, pela redução com borohidreto de sódio, ou ainda no sentido de se obter um derivado cristalino, todas sem sucesso. A análise por espectrometria de massas por spray de íons também não se mostrou eficaz, sugerindo uma estrutura dimérica do tipo (42). A única forma dos autores sugerirem a estrutura polimérica de (41) foi pela síntese de vários análogos (ver ítem Síntese, abaixo). O produto natural mostrou ser o mais ativo no teste aplicado (inibição da atividade da enzima denominada "fator de crescimento da epiderme"; IC IC $_{50} 2 \mu \mathrm{g}$ / $\mathrm{mL}$ ) em comparação com os análogos sintetizados.

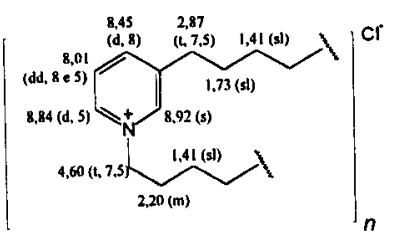

(41) (RMN-IH $\left.500 \mathrm{MHz}, \mathrm{CD}_{3} \mathrm{OD}\right)$

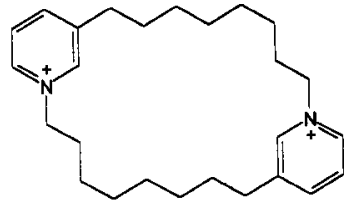

(42)
Por fim, recentemente Albrizio et al. ${ }^{96}$ isolaram a amphitoxina (43) da esponja Amphimedon compressa. Numa expedição ao longo das costas das Bahamas, os autores notaram que, enquanto alguns espécimens desta esponja possuíam a halitoxina (1), outros possuíam a amphitoxina (43). Como no caso da halitoxina (1), a amphitoxina (43) foi isolada sob forma de uma mistura de polímeros em duas frações de diferentes massas moleculares (1.000-3.000 Da e 3.000-10.000 Da), obtidas por cromatografia "relâmpago" em sílica-gel $\left(\mathrm{CHCl}_{3}-\mathrm{MeOH}-\right.$ $\mathrm{H}_{2} \mathrm{O}, \mathrm{MeOH}$ e $5 \% \mathrm{AcOH}$ em $\left.\mathrm{MeOH}\right)$ e filtração em membranas. O produto foi caracterizado por diversas técnicas espectroscópicas, e também por degradação química: a ozonólise da amphitoxina (43) seguida de tratamento com peróxido de hidrogênio forneceu o diácido (44). A análise estrutural indicou uma proporção relativa de $1: 1$ das duas cadeias alifáticas, saturada e insaturada, na estrutura da amphitoxina. A amphitoxina possui atividade fago-repelente, inibindo a predação por parte do peixe Thalassoma bifasciatum. Os autores discutem o fato de que ainda não se sabe qual a razão pela qual a mesma espécie de esponja, A. compressa, quando originária de diferentes regiões, ora possui a halitoxina (1), originalmente isolada da mesma esponja por Schmitz et al. ${ }^{77,78}$, ora possui a amphitoxina (43). Cabe ressaltar que, tanto a halitoxina isolada por Schmitz e colaboradores de A. compressa ${ }^{77}$ como aquela por nós isolada de $A$. viridis ${ }^{81}$ apresenta, em seu espectro de RMN $-{ }^{1} \mathrm{H}$, sinais de impurezas entre 5.00 e $5.50 \mathrm{ppm}$, bem como em $3.70 \mathrm{ppm}$, o que provavelmente indica uma contaminação das diferentes halitoxinas pela amphitoxina. Estes sinais podem ser atribuídos aos prótons olefínicos (5.00 e $5.50 \mathrm{ppm})$ e ao metileno entre a ligação dupla e o anel piridínico (3.70 ppm), como assinalado na subestrutura de cadeia insaturada da amphitoxina (43).

\section{SÍNTESE}

Vários trabalhos discutem a síntese de alcalóides alquilpiridínicos de esponjas marinhas. As primeiras sínteses desta classe

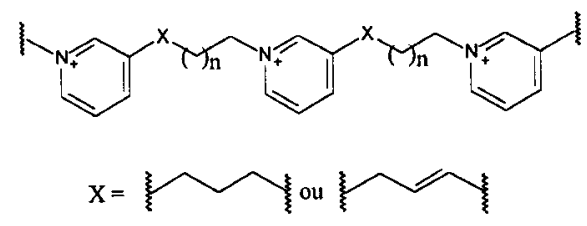

(43) $n=5$
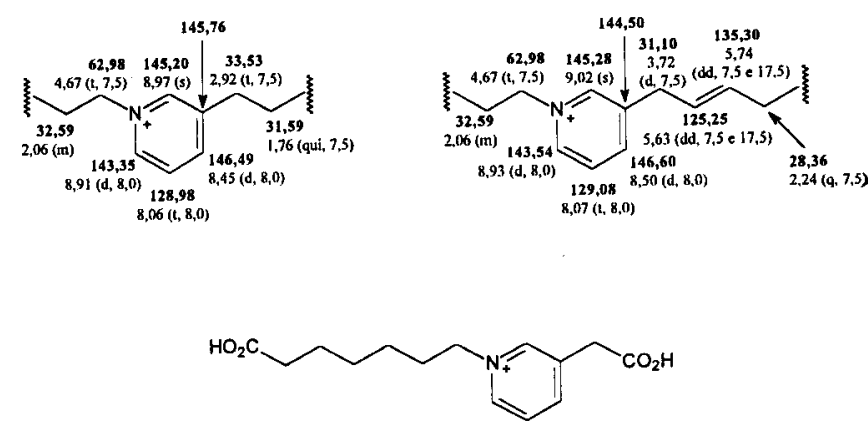

(44) 
de compostos foi apresentada em 1991 por Rao, Reddy e Rao ${ }^{97}$, que desenvolveram duas rotas diferentes para a síntese das teoneladinas A-D (4) - (7). Na primeira delas (Esquemas 1 e 2), os autores utilizam o 3-(3-piridil)-propan-1-ol (45) como composto de partida, sobre o qual realizaram uma oxidação de Swern, seguido da condensação de Wittig com o sal de fosfônio do 1-bromoundecanol protegido por um grupo tetrahidropirano. $\mathrm{O}$ produto (47), obtido de maneira estereosseletiva, teve a configuração da ligação dupla confirmada por análise de seus espectros de $\mathrm{RMN}-{ }^{1} \mathrm{H}$ e $\mathrm{RMN}-{ }^{13} \mathrm{C}$. Após a remoção do grupo de proteção tetrahidropirano por hidrólise em meio ácido, o álcool primário (48) foi oxidado ao aldeído correspondente (49) também pela oxidação de Swern. O produto obtido foi diretamente transformado nas teoneladinas A (4) e B (5) pela condensação com uma amina adequada, fornecendo a imina correspondente, a qual foi subsequentemente reduzida, fornecendo os produtos naturais. A síntese das teoneladinas C (6) e D (7) (Esquema 2) foi realizada de maneira análoga, sendo que o intermediário insaturado (47) foi hidrogenado de maneira a fornecer a cadeia saturada precursora para a formação das teoneladinas C (6) e D (7). Na segunda rota (Esquema 3), os dibrometos $(\mathbf{5 2}, \mathrm{n}=10$ ou 11) foram transformados em seus respectivos sais de fosfônio $(\mathbf{5 3}, \mathrm{n}=10$ ou 11) e estes subsequentemente em suas respectivas azidas $(\mathbf{5 4}, \mathrm{n}=10$ ou 11). Estas, por sua vez, foram condensadas com o aldeído previamente obtido, fornecendo as alquenilpiridinas $(\mathbf{5 5}, \mathrm{n}=9$ ou 10). Por um lado, o homólogo inferior $(\mathbf{5 5}, \mathrm{n}=9)$ foi subsequentemente transformado (por redução da ligação dupla e da função azida) na teoneladina $\mathrm{C}(\mathbf{6})$, da qual parte foi tratada

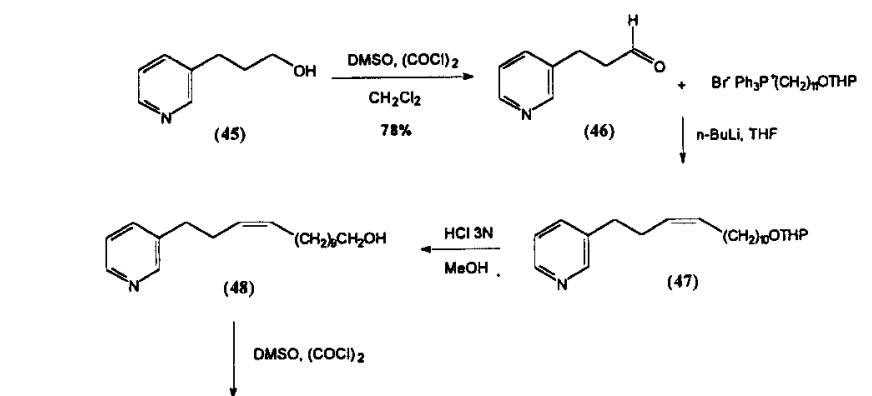

1

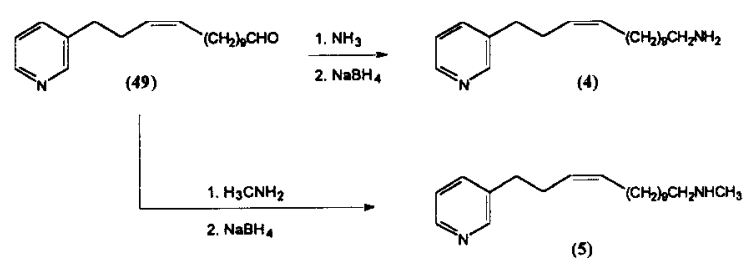

Esquema I

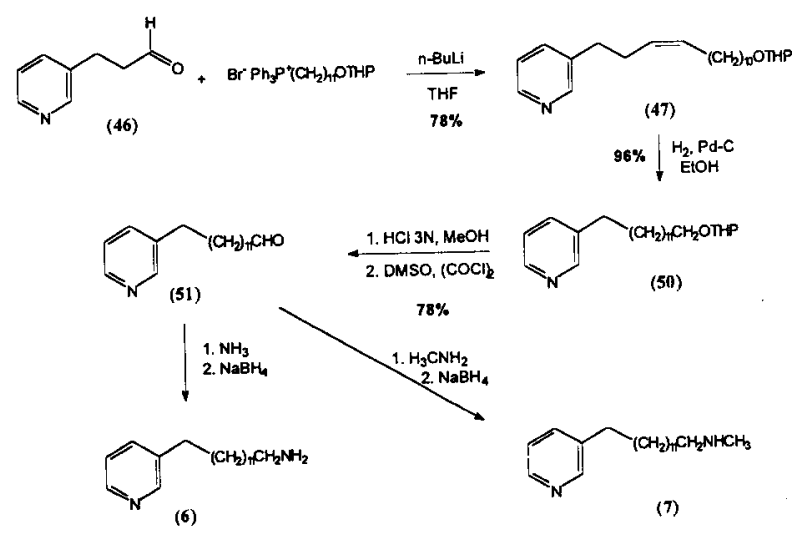

Esquema 2 com o anidrido mixto dos ácidos fórmico e acético e posteriormente reduzido, de maneira a fornecer a teoneladina D (7). A obtenção da teoneladina B (5) é ambígua, sendo indicado tanto a redução com borohidreto de sódio (no esquema indicado na discussão dos autores) como por hidreto de lítio e alumínio (na parte experimental) da função formila após a acilação da teoneladina A (4). Acreditamos que a redução com hidreto de lítio e alumínio deve ter sido empregada para a redução da função formila, já que o borohidreto de sódio é um redutor brando e pouco eficaz para a redução de funções amida ${ }^{98}$.

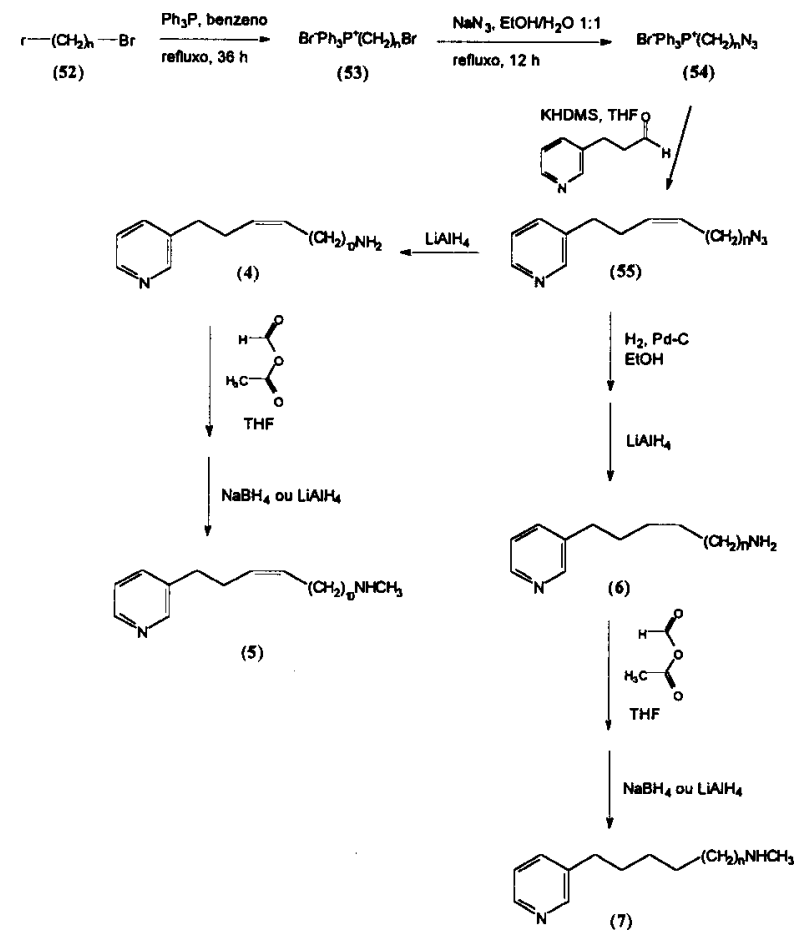

Esquema 3

Uma síntese convergente das nifatesinas A - D (17) - (20), bem como a determinação de sua configuração absoluta, foi realizada por estes mesmos autores ${ }^{99}$ (Esquemas 4, 5 e 6). A piridina-3-carboxaldeído (56) foi submetida à reação de Wittig com o ilídio preparado a partir do brometo de metiltrifenilfosfônio, fornecendo a 3-vinilpiridina (57). Esta foi subsequentemente transformada no brometo $(\mathbf{5 8})$, o qual foi diretamente acoplado com a segunda metade das nifatesinas, obtida como se segue: o cloreto de tetrahidrofurila (59) foi convertido no álcool acetilênico $(\mathbf{6 0})$ pelo tratamento com amideto de lítio em amônia seguido da alquilação do acetilídeo obtido com o brometo de n-heptila. O produto (60) foi então submetido à reação de Zipper, fornecendo o carbinol acetilênico terminal (61), o qual foi convertido em sua respectiva azida (62) via a reação de Mitsunobu. A azida (62) foi então acoplada à bromopiridina $(\mathbf{5 8})$ previamente obtida, fornecendo a azidopiridina (63), a qual, após redução com hidreto de lítio e alumínio, forneceu a nifatesina A (17) (Esquema 4). A nifatesina B (18) foi sintetizada (Esquema 5) a partir do álcool (61), reduzindo-se este com catalizador envenenado de Lindlar, fornecendo o álcool insaturado (64). Este foi acoplado com a 3-bromopiridina (65) por uma reação de acoplamento do tipo Heck, a qual passa pela formação de um brometo de piridil paládio intermediário, fornecendo seletivamente a olefina $E$ (66). Após redução da ligação dupla, o álcool (67) foi transformado em seu respectivo brometo $(\mathbf{6 8})$, ao qual foi acoplada a azida (62), fornecendo o precursor direto (69) da nifatesina B (18) (Esquema 5). 


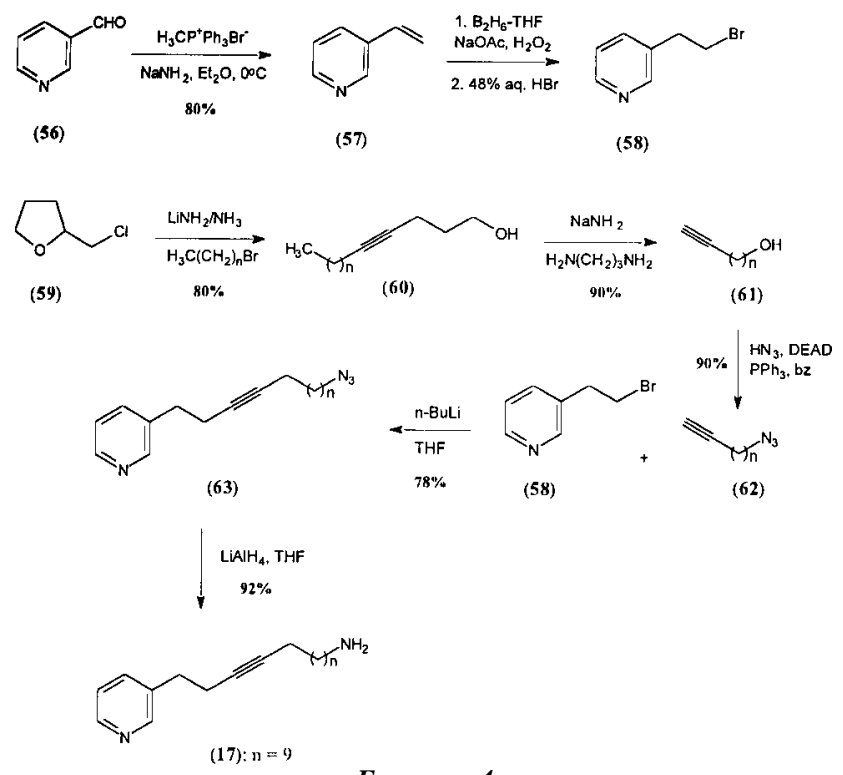

Esquema 4

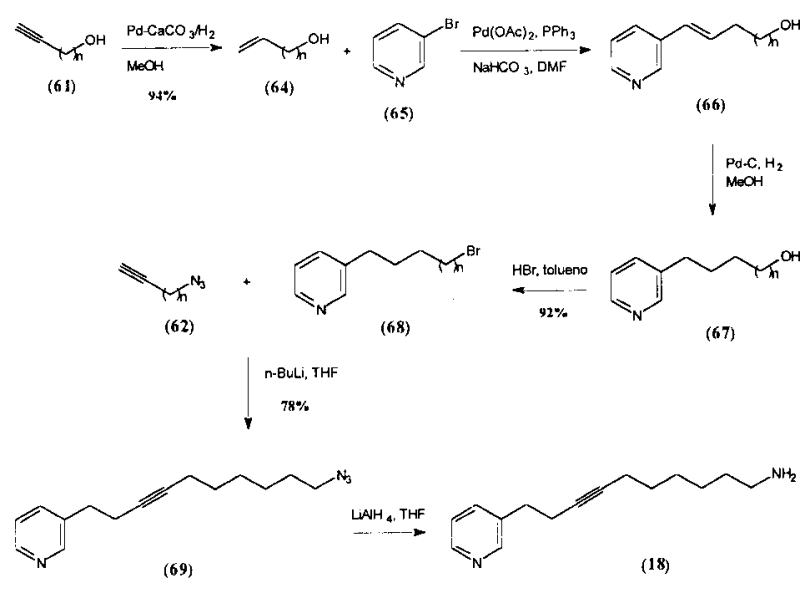

Esquema 5

No que se refere à síntese das nifatesinas ópticamente ativas (19) e (20), o álcool (67) previamente obtido foi oxidado ao seu aldeído correspondente (70) pela oxidação de Swern. O aldeído (70) foi então acoplado por uma reação de Wittig ao ilídeo quiral (71), obtido a partir do ácido $(R)$-(-)-metil-3hidroxi-2-metilpropiônico. A 3-alquilpiridina quiral (72) foi convertida na nifatesina $C(\mathbf{1 9})$ através de sua conversão à azida (73) e subsequente redução de ambas ligação dupla e grupo azida por hidrogenação catalítica. Alternativamente, a mesma olefina quiral (72) foi transformada na nifatesina D (20) após sua conversão ao tosilato correspondente, substituição com cianureto de sódio fornecendo a nitrila e finalmente hidrogenação catalítica (Esquema 6).

Recentemente Bracher e Papke desenvolveram uma nova rota sintética para a síntese enantioseletiva das nifatesinas ${ }^{100}$ (Esquema 7). A acilação de Friedel-Crafts do enantiômero $(S)$ do tiofeno (75) com o cloridrato do cloreto do ácido 5-(3piridil)pentanóico (74) forneceu a tienil cetona (76). Esta foi simultaneamente reduzida (Huang-Minlon) e o éster hidrolisado, levando à formação de (77). A dessulfurização de (77) foi realizada com Níquel de Raney e hidrogênio à temperatura ambiente. Os autores justificam o rendimento de $62 \%$ desta reação em parte devido à adsorção do produto na superfície do catalizador. $\mathrm{O}$ álcool $\mathbf{( 7 8 )}$ foi então convertido à nifatesina $\mathrm{C}$ (19) através da sua transformação no mesilato (79), seguido da azida $(\mathbf{8 0})$ e a redução desta levando ao produto desejado (19).
$\underset{\mathrm{Et}_{3} \mathrm{~N}_{1} \mathrm{CH}_{2} \mathrm{Cl}_{2}}{\left(\mathrm{COCl}_{2}, \mathrm{OMSO}\right.}$

(67)

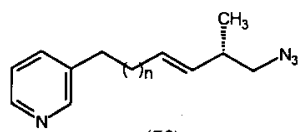

(73)

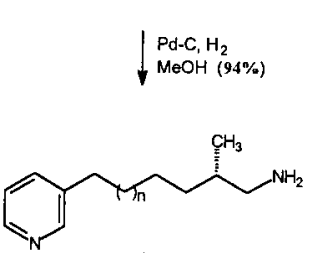

(19)

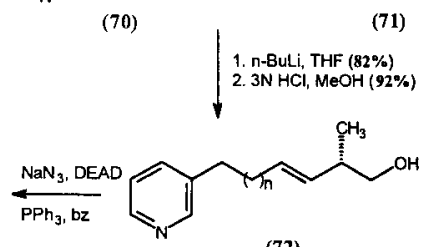

(72)

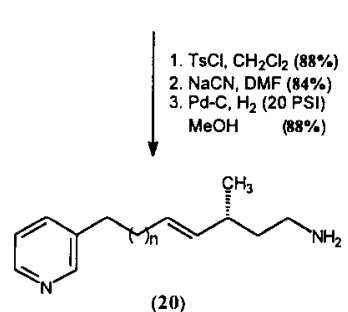

(20)

Ësquema 6
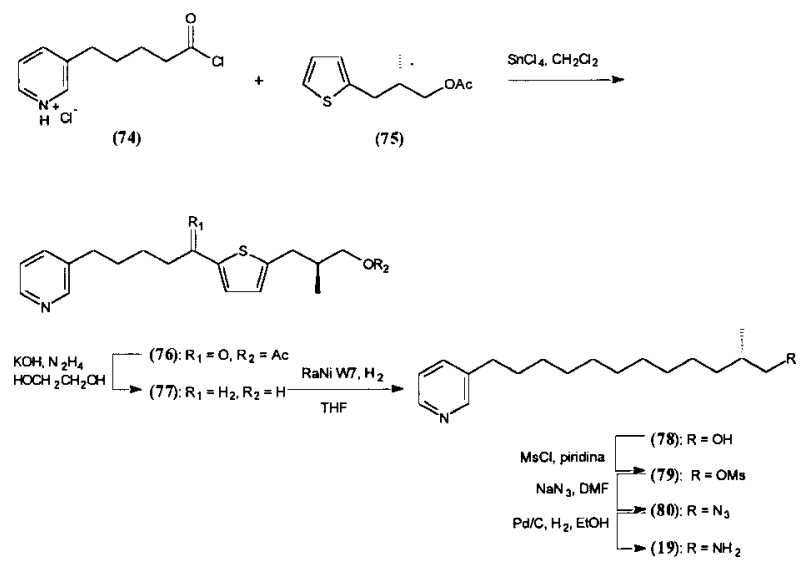

Esquema 7

Com o intuito de confirmar a estrutura proposta para o alcalóide alquilpiridínio (41) isolado da esponja Callyspongia fibrosa, Davies-Coleman et al. ${ }^{95}$ realizaram a síntese de derivados com diferentes números de unidades alquilpiridínio. Inicialmente, diferentes homólogos (84, n = 1-3) dos álcoois piridínicos foram sintetizados a partir de diferentes bromocarbinóis $(\mathbf{8 1}, \mathrm{n}=1-3)$ (Esquema 8). Com o intuito de promover a oligomerização cíclica das unidades alquilpiridina, o grupo carbinol de (84) foi convertido em tosilato (85), tendo sido observada uma pequena porcentagem de formação do dipiridilalquiléter (86) durante esta reação. Optou-se então por ativar a nucleofilia do grupo piridínio, promovendo-se sua desprotonoção com diisopropiletilamina, formando a base livre (87). Esta foi submetida à ciclização oligomérica. $\mathrm{Em} \mathrm{CH}_{2} \mathrm{Cl}_{2}$, observou-se a obtenção de $0,9 \%$ do dímero $(\mathbf{8 8}), 33 \%$ do tosilato de monoalquilpiridínio (89) e $66 \%$ do produto de partida $(\mathbf{8 7})$. Já em $N$-metilpirrolidinona na presença de cloreto de césio, a proporção dos produtos obtidos foi de $14 \%$ de $(\mathbf{8 8}), 23 \%$ de (89) e $63 \%$ de (87). Objetivando-se incrementar a formação de diferentes oligômeros, os diferentes homólogos dos álcoois piridínicos (84, $\mathrm{n}=1-3)$ foram transformados em seus respectivos triflatos, e, por simples aquecimento do meio reacional, nos oligômeros (90), (91) e (92), com n variando de acordo com o álcool piridínico (84) utilizado como substrato (Esquema 9). Para cada série de homólogos sintetizada os três produtos obtidos foram eficientemente separados por cromatografia em sílica-gel. Os autores assinalam que, para que ocorra uma eficiente ciclização oligomérica, a concentração dos reagentes 

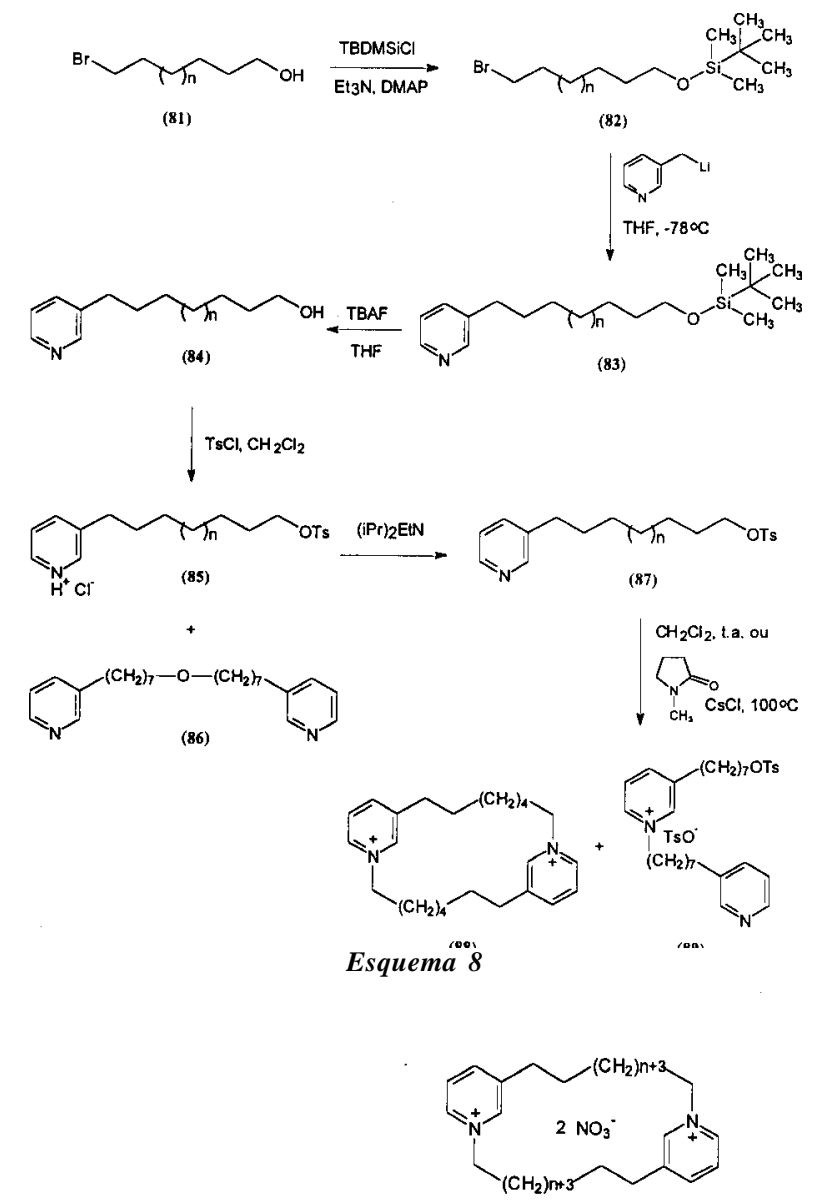

(90)
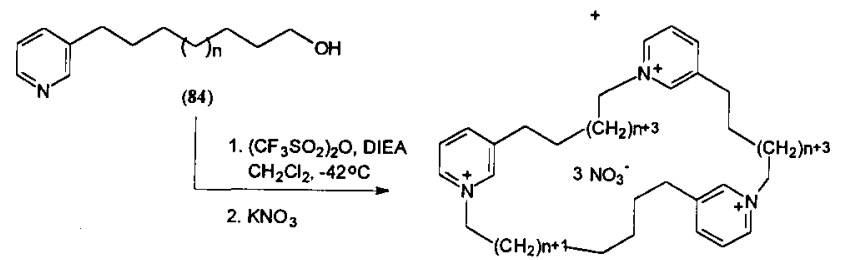

(91)

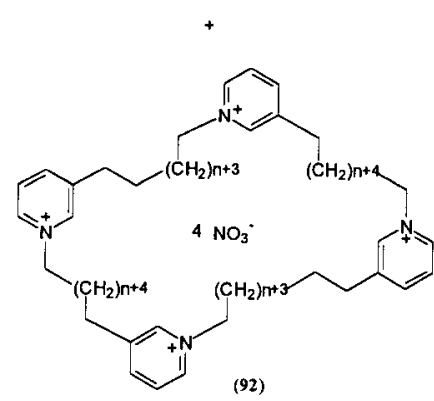

Esquema 9

no meio reacional deve ser maior que $0,4 \mathrm{M}$. A comparação do comportamento cromatográfico (por cromatografia em camada delgada) dos produtos de síntese com o produto natural indicou que nenhum dos produtos obtidos por síntese correspondia ao composto (41) isolado de Callyspongia fibrosa.

Uma segunda abordagem para a síntese de análogos de alcalóides alquilpiridínicos macrocíclicos de esponjas marinhas foi recentemente descrita ${ }^{101}$ (Esquema 10), e utiliza-se de uma

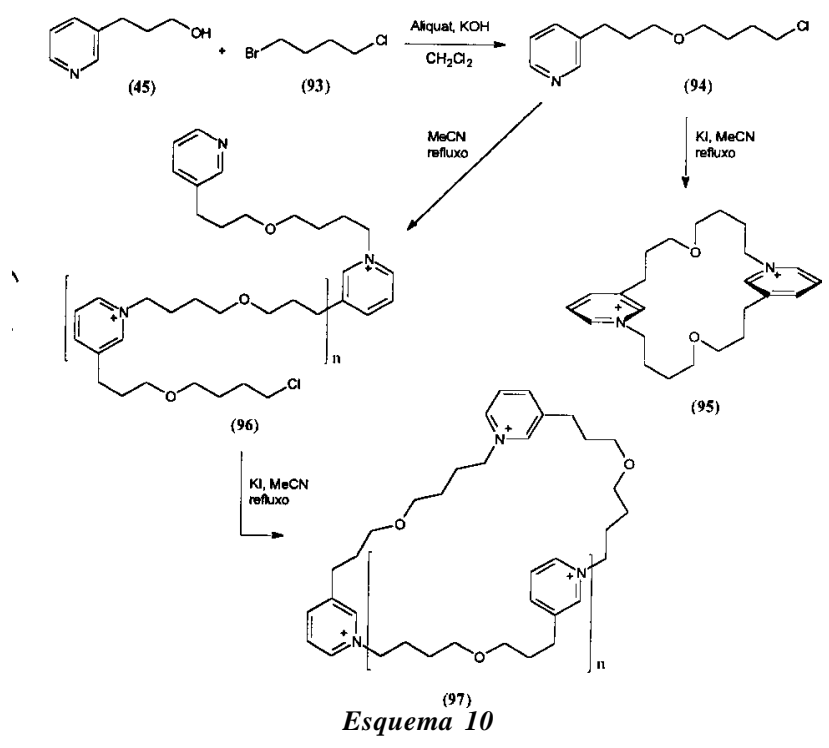

estratégia que envolve o controle do grau de polimerização de unidades 3-alquilpiridínicas sob diferentes condições. Assim, o monômero (94) foi obtido pela reação entre 3-(3-piridil)propan-1-ol (45) e 1-bromo-4-clorobutano (93). Observou-se a dimerização do monômero (94) quando a reação de polimerização foi realizada sob refluxo em acetonitrila na presença de iodeto de potássio. O dímero formado, (95), foi identificado por difração de raios-X. Por outro lado, a reação do monômero (94) sob refluxo em acetonitrila levou à formação de uma mistura de polímeros lineares (96), com n variando de 0 a 14 dependendo do tempo da reação (entre uma e várias semanas). Sua posterior ciclização, de forma a levar aos respectivos polímeros cíclicos (97), mostrou resultados variáveis, também de acordo com o período de realização da reação. Além disso, novamente notou-se a formação do dímero $(\mathbf{9 5})$, indicando que possivelmente os polímeros cíclicos (97) são sujeitos à clivagem por iodeto, seguido da reciclização. Fato interessante, os autores assinalam que, em testes de citotoxicidade em células de linhagem $\mathrm{KB}$, os polímeros cíclicos de maior massa molecular $(7<\mathrm{n}<14)$ apresentaram a atividade mais potente dentre os produtos obtidos, com um grau de atividade comparável ao da halitoxina (1).

A redução do dímero (95) com borohidreto de sódio (Esquema 11) levou à formação da tetrahidropirimidina dimérica (98), a qual foi subsequentemente oxidada e o respectivo $N$ óxido quaternizado, de maneira a fornecer o sal de bisdihidropiridínio (99). Este último foi tratado com metóxido de sódio em metanol, de maneira a fornecer regiosseletivamente o dímero (100). Sob aquecimento em tolueno, este último foi transformado na bis 1,4-dihidropiridina (102), possivelmente via a bis-1,6-dihidropiridina (101), esta última considerada um precursor biogenético potencial de alcalóides do tipo manzamina (ver Biossíntese e Quimiotaxonomia, a seguir).

\section{BIOSSÍNTESE E QUIMIOTAXONOMIA}

As esponjas marinhas foram objeto de intensos estudos no que se refere à sua composição química e bioquímica, com vistas à utilização de metabólitos primários ou secundários como marcadores quimiotaxonômicos ${ }^{17-19}$. Isso se deve principalmente à escassez de caracteres anatômicos de fácil observação por métodos convencionais (microscopia óptica) em boa parte das espécies de Porifera, mas também devido à plasticidade morfológica de muitos destes caracteres e à inexistência, até recentemente, de métodos objetivos para o reconhecimento de determinados grupos de esponjas ${ }^{8,107-109}$. Contudo, poucos 

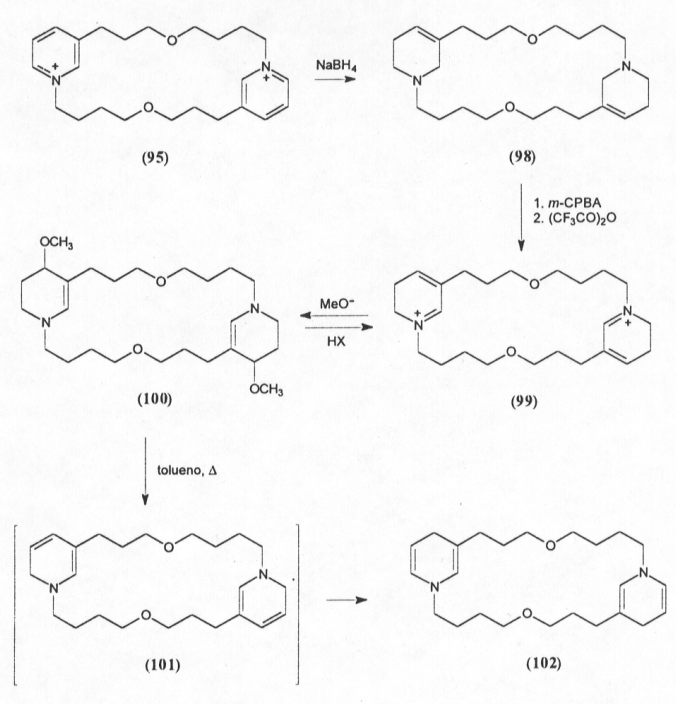

Esquema 11

estudos quimiotaxonômicos foram conclusivos, o que se deve em parte à grande diversidade estrutural dos compostos originários de esponjas marinhas, bem como à seleção pouco criteriosa das espécies a serem analisadas quimiotaxonomicamente. Alguns exemplos de abordagens quimiotaxonômicas em poríferos se referem à ocorrência de derivados da bromotirosina em esponjas da Ordem Verongida e esponjas do gênero Ianthella (ou sinônimos, como Pseudoceratina e Aiolochroia $)^{17,40,102,103}$, alcalóides guanidínicos e 2-aminoimidazólicos derivados de bromopirróis em esponjas do Gênero Agelas $^{18,40}$, bem como terpenos recorrentes em esponjas das Ordens Dictyoceratida e Dendroceratida ${ }^{17,40}$. Baseando-se nestes resultados, pode-se, eventualmente, realizar análises de extratos brutos por espectroscopia no infravermelho, procurando absorções características de determinados grupos funcionais presentes em compostos característicos de esponjas de Ordens, Famílias ou Gêneros específicos ${ }^{104}$. Outras abordagens foram propostas $^{105}$, não sem apresentar limitações à sua aplicação ${ }^{106}$. Deve-se ressaltar, porém, que análises quimiotaxonômicas de esponjas marinhas devem ser realizadas com cautela, visto que estes animais frequentemente se encontram em associação com uma grande variedade de bactérias e algas verde-azuladas (cianofíceas), sendo, assim, difícil de se estabelecer a correta origem biossintética dos compostos isolados. Outro ponto revelante é a dificuldade em se realizar experimentos de biossíntese com esponjas marinhas, pois estes animais possuem um metabolismo extremamente lento e são de difícil manutenção em aquários, o que constitui uma severa limitação para a realização de experimentos desta natureza ${ }^{110}$.

No que se refere aos alcalóides alquilpiridínicos de esponjas marinhas, nenhuma proposta foi até então levantada sobre a origem biossintética destes compostos, bem como de sua ocorrência em esponjas da Ordem Haplosclerida. Baldwin e Whitehead ${ }^{111,112}$ recentemente sugeriram uma rota de biossíntese para alcalóides do tipo manzamina A (103), manzamina B (104) e manzamina $C(\mathbf{1 0 5})$ e análogos, isolados de esponjas do gênero Haliclona ${ }^{113,116}$, Pellina ${ }^{114}$, Pachypellina ${ }^{115}$, Xestospongia $^{117}$, Reniera ${ }^{118-121}$ [p. ex., saraina-1 (106) e saraina A (107)], Ircinia ${ }^{122}$, e Amphimedon ${ }^{123-125}$ [p. ex., ircinol B (108)] na qual a origem biogenética de alcalóides do tipo manzamina C (105) é postulada como sendo originária da condensação de uma unidade constituída por 10 átomos de carbono (proveniente da condensação de unidades acetato), uma unidade com 3 átomos de carbono análoga à acroleína, amônia e uma unidade triptofano, segundo ilustrado no Esquema 12. Já os alcalóides

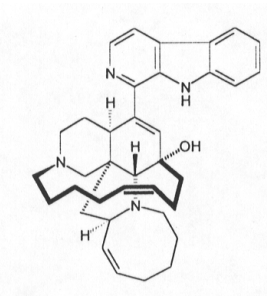

(103): manzamina $\wedge$

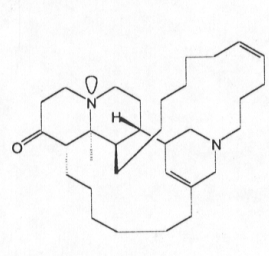

(106)

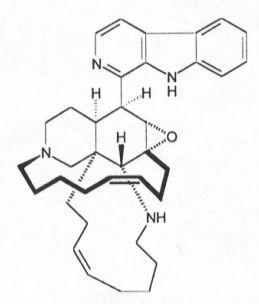

(104): manzamina B

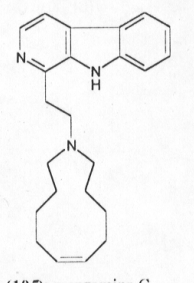

(105): manzamina C

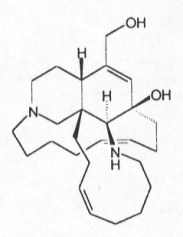

(108)

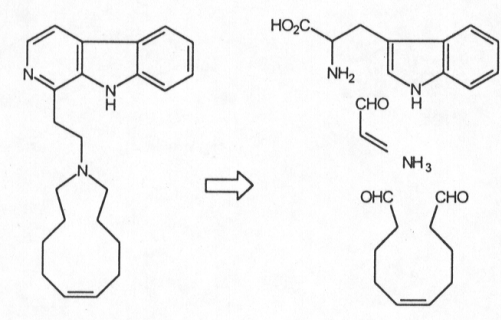

(105)

Esquema 12

Tabela 1. Classificação taxonômica das espécies de esponjas marinhas fontes de alcalóides 3-alquilpiridínicos.

\begin{tabular}{|c|c|c|c|c|c|c|}
\hline Subclasse & Ordem & Família & Gênero & Espécie & Alcalóide(s) isolado(s) & Ref. \\
\hline \multirow[t]{2}{*}{ Tetractinomorpha } & Astrophorida & Stellettidae & Stelletta & S. maxima & $35,36,37,38,39,40$ & 94 \\
\hline & Lithistida & Theonellidae & Theonella & T. swinhoei & $4,5,6,7$ & 84 \\
\hline \multirow[t]{9}{*}{ Ceractinomorpha } & Haplosclerida & Petrosidae & Xestospongia & $X$. wiedenmayeri & $25,26,27$ & 91 \\
\hline & & Niphatidae & Amphimedon & A. viridis & 1 & 81 \\
\hline & & & & A. compressa & 1,43 & $77,78,96$ \\
\hline & & & Niphates & Niphates sp. & 2,3 & 83 \\
\hline & & & & Niphates sp. & $17,18,19,20,21,22,23,24$ & 88,90 \\
\hline & & & & Niphates sp. & 33,34 & 93 \\
\hline & & & Cribrochalina & Cribrochalina sp. & 14,15 & 87 \\
\hline & & Phloeodictyidae & Calyx & C. podatypa & $28,29,30,31,32$ & 92 \\
\hline & & Callyspongidae & Callyspongia & C. fibrosa & 41 & 95 \\
\hline
\end{tabular}


do tipo manzamina B (104) seriam provenientes da condensação de duas unidades $C_{10}$, duas unidades $C_{3}$, amônia e uma unidade triptofano, segundo a rota retrobiossintética proposta por Baldwin e Whitehead ${ }^{111,112}$ (Esquema 13). A biogênese de alcalóides do tipo manzamina A teria origem análoga aos alcalóides do tipo manzamina $\mathrm{B}$, com algumas etapas adicionais para a formação do sistema pentacíclico. Os autores não somente propuseram a origem biossintética destes alcalóides, como também assinalaram que intermediários da rota de biossíntese de alcalóides do tipo manzamina A e B, notadamente (109) (Esquema 13), seriam possivelmente isolados de espécies correlatas de esponjas marinhas. De fato, apesar de não mencionadas por Baldwin e Whitehead, as haliclaminas A (110) e B (111) foram previamente isoladas de uma esponja do gênero Haliclona ${ }^{126}$. A proposta destes autores vai de encontro àquela inicialmente levantada por Cimino et al. ${ }^{119,120}$, que sugeriram uma origem biogenética comum para diferentes classes de alcalóides isolados de esponjas da Ordem Haplosclerida, incluindo não somente aqueles acima mencionados, como também alcalóides do tipo petrosinas de esponjas do gênero Petrosia ${ }^{127,128}$ [p. ex., petrosina A (112)], xestosponginas de esponjas do gênero Xestospongia ${ }^{129}$ [p. ex., xestospongina A (113)] e halitoxinas. Além destes, pode-se incluir igualmente a papuamina (=haliclodiamina) (114) isoladas de dois diferentes espécimens de Haliclona ${ }^{130,131}$. Recentemente uma grande variedade de substâncias correlatas foi isolada de uma série de esponjas da ordem Haplosclerida: as xestociclaminas A (115) e B (116), de Xestospongia sp. ${ }^{132-134}$, a ingenamina (117) e ingaminas A e B análogas de Xestospongia ingens ${ }^{135,136}$, a madangamina A (118) igualmente de Xestospongia ingens ${ }^{136}$, a haliciclamina A (119) de Haliclona sp. ${ }^{137}$, duas 1,2,3,4-tetrahidro-8-hidroximanzaminas isoladas de duas esponjas, Petrosia contignata e Cribrochalina sp. ${ }^{138}$, e a kauluamina (120), recentemente isolada da esponja Prianos sp. ${ }^{139}$. O isolamento da keramafidina C (121) e da keramamina C (122), junto da keramafidina B (123) da esponja Amphimedon sp. ${ }^{140,141}$ praticamente corrobora a hipótese de biossíntese de Baldwin e Whitehead.

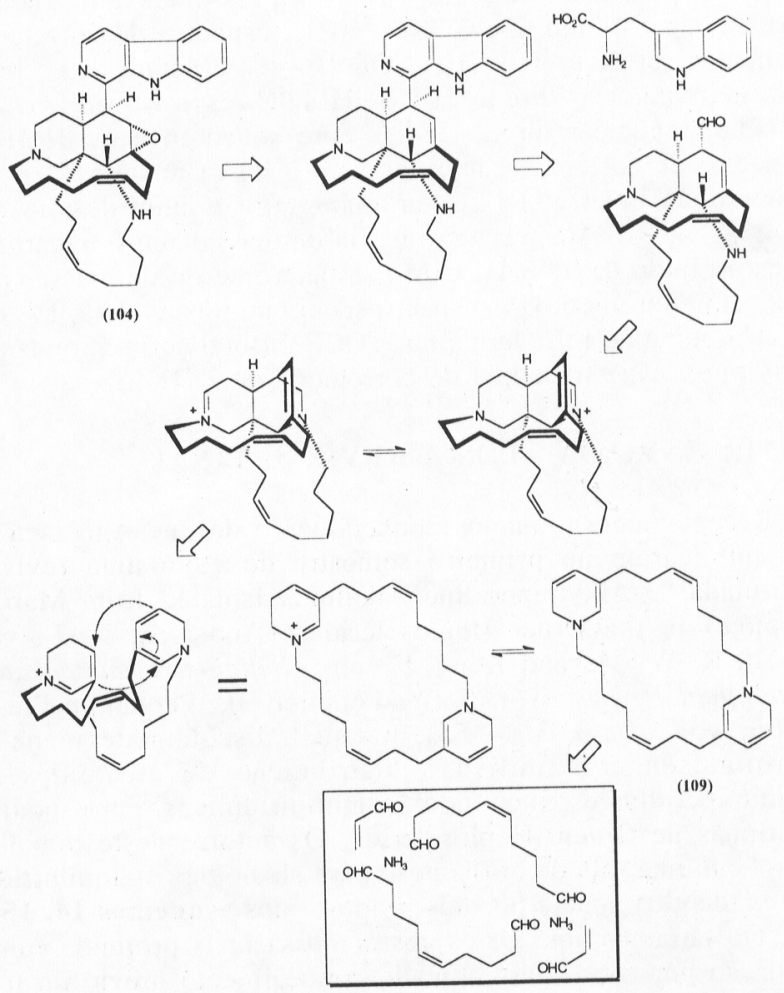

Na maioria destas últimas referências ${ }^{132-134,136-141}$ os autores propõem rotas de biossíntese para os compostos isolados baseadas na proposta original de Whitehead e Baldwin. Além disso, Crews et al. ${ }^{138}$ sugerem, pela primeira vez, a utilização destes alcalóides como marcadores quimiotaxonômicos, excluíndo, contudo, a maioria dos alcalóides 3-alquilpiridínicos, exceção feita às ciclostelletaminas A-F $(\mathbf{3 5})-(\mathbf{4 0})^{94}$.

Tendo-se em vista as estruturas das haliclaminas A (110) e B (111), não se pode deixar de notar seu paralelismo com alcalóides alquilpiridínicos como as ciclostelletaminas (35)-(40) isoladas de Stelleta maxima, ou ainda as nifatoxinas (33) e (34) de Nifates sp. Outro fato que merece destaque é que a maioria dos alcalóides alquilpiridínicos, do tipo manzaminas A-C e análogos, haliclaminas, petrosinas, xestosponginas e os

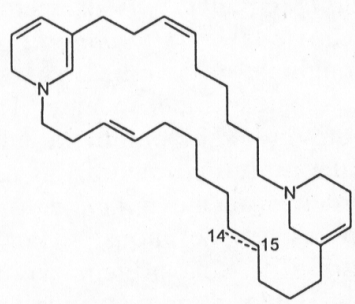

(110): haliclamina $\Lambda$ (111): $\Delta^{14,15}$, haliclamina B

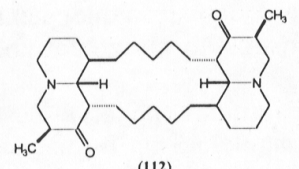

(112)

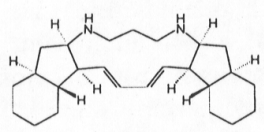

(114)

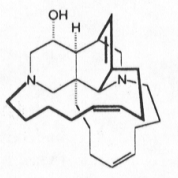

(116)

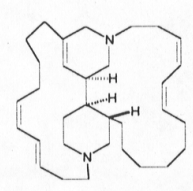

(119)

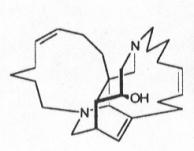

(117)

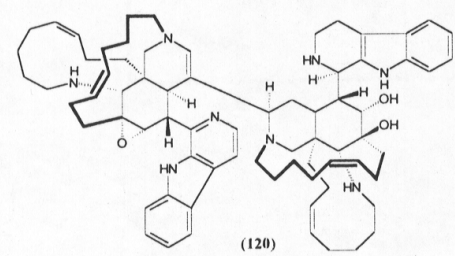

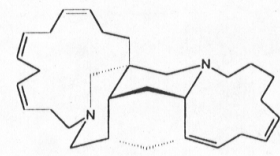
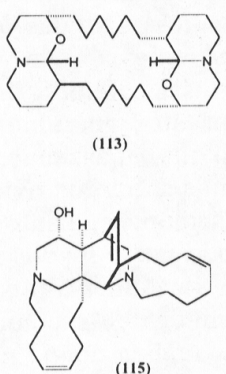

Esquema 13

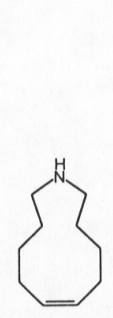

(121)

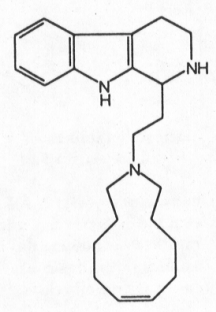

(122)

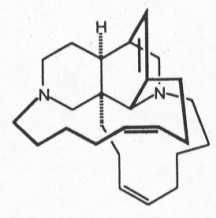

(123) 
outros mencionados foram isolados de esponjas da Ordem Haplosclerida, com exceção feita àqueles isolados das esponjas Ircinia sp. ${ }^{121}$ (Subclasse Ceractinomorpha, Ordem Dictyoceratida, Familia Thorectidae), Theonella swinhoei ${ }^{84}$ (Subclasse Tetractinomorpha, Ordem Lithistida, Familia Theonellidae) e Stelleta maxima ${ }^{94}$ (Subclasse Teractinomorpha, Ordem Choristida, Familia Stelletidae). O gênero Prianos ${ }^{139}$ provavelmente pertence à Ordem Haplosclerida, e não Poescilosclerida como assinalado pelos autores. Além disso, considera-se o gênero Prianos como uma variedade de Xestospongia, este último estreitamente relacionado ao gênero Haliclona. Cabe ainda assinalar que o voucher de Stelleta maxima ${ }^{94}$ foi revisto por van Soest, que observou a presença de uma espécie do gênero Haliclona recobrindo $S$. maxima ${ }^{142}$, colocando em dúvida a origem dos compostos isolados. A ocorrência de alcalóides alquilpiridínicos em esponjas do gênero Amphimedon, Callyspongia, Cribrochalina e Niphates (todas pertencentes à Familia Niphatidae, exceção feita à Callyspongia, atualmente pertencente às Callyspongidae ${ }^{143}$ ) deve-se possivelmente à herança genética e não à aquisição independente. Tais compostos podem ser uma bemvinda sinapomorfia adicional (i.e., um caractere que define um grupo natural) às esponjas da Ordem Haplosclerida, Ordem esta até o momento caracterizada por caracteres anatômicos mal definidos ${ }^{144}$. Por outro lado, o suporte para a hipótese de uma origem evolutiva comum para esponjas da Ordem Haplosclerida depende tanto do isolamento de outros metabólitos secundários relacionados biogeneticamente como a verificação de que compostos correlatos isolados de gêneros distantes (Stelletta, Theonella) se deve ou à homoplasticidade (paralelismo evolutivo) ou à aquisição independente (rotas biogenéticas distintas ou transmissão horizontal através de microssimbiontes).

No caso dos alcalóides alquilpiridínicos, poderia se supor que sua formação segue uma rota paralela à da formação dos alcalóides do tipo manzamina, na qual os intermediários do tipo haliclamina sofreriam oxidação, dando origem aos núcleos aromáticos piridínicos, conforme os Esquemas 14, 15 e 16. Fundamentando nossa hipótese, Crews et al. ${ }^{138}$ incluiram, pela primeira vez, alcalóides 3-alquilpiridínicos na rota de biossíntese dos alcalóides de esponjas da Ordem Haplosclerida. Porém, como a realização de experiências de incorporação de compostos marcados isotopicamente em esponjas marinhas é

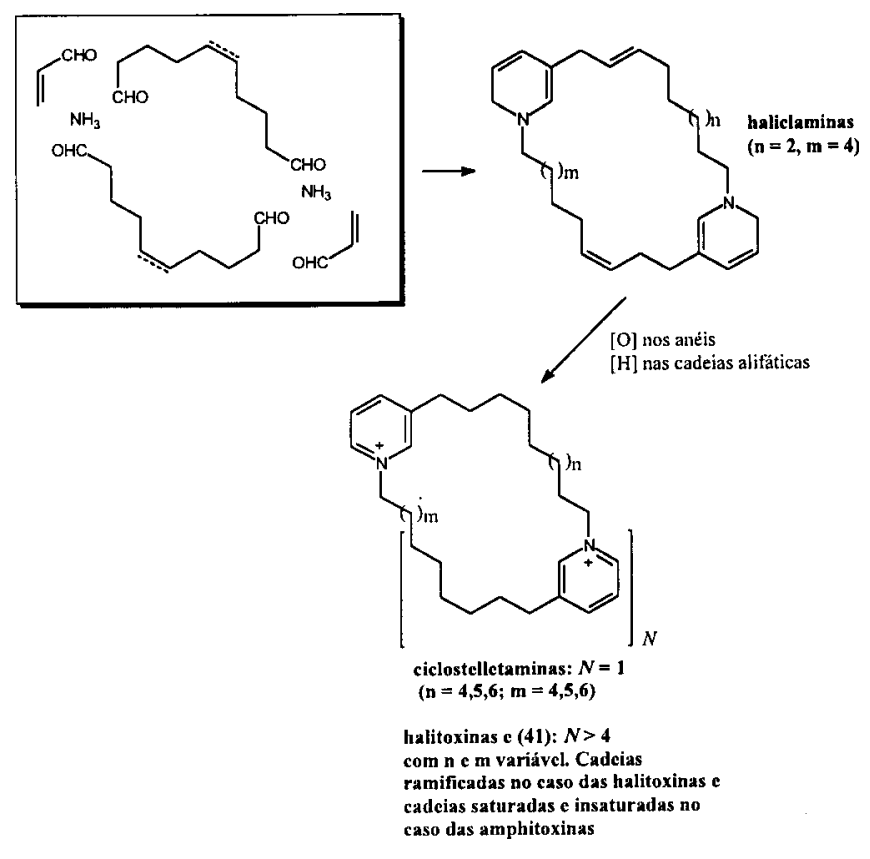

Esquema 14

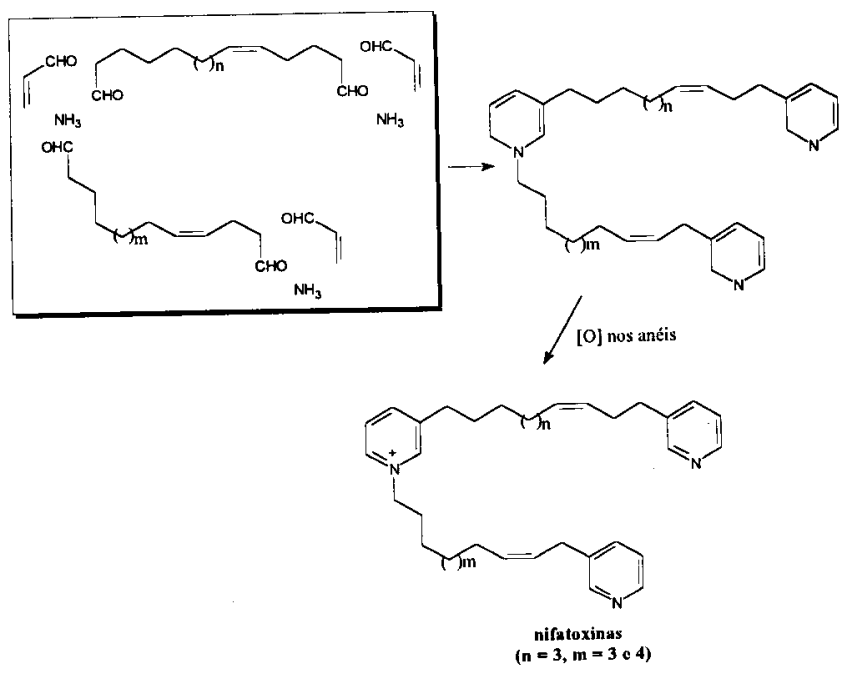

Esquema 15

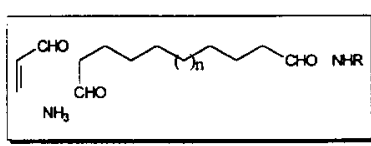

1. $[0 \mid$ nos ancis

2.Funcionalizuçăo dus cadeins ulifúticas

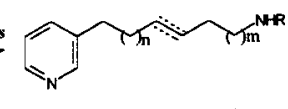
teoneladinas, cribrochalinaminas nifatinus, ikinainas, nifatesinus xestaminas

Esquema 16

severamente limitada pelos motivos expostos acima, acreditamos que dificilmente quaisquer destas hipóteses poderá ser verificada experimentalmente.

\section{ABREVIAÇÕES E LEGENDAS PARA AS ESTRUTURAS}

*, atribuições intercambiáveis; $\mathrm{RMN}-{ }^{1} \mathrm{H}$, ressonância magnética nuclear de hidrogênio; $\mathrm{RMN}^{13} \mathrm{C}$, ressonância magnética nuclear de carbono 13; COSY ${ }^{1} \mathrm{H}^{-1} \mathrm{H}$, espectro de correlação homonuclear de próton; HETCOR ${ }^{1} \mathrm{H}_{-}{ }^{13} \mathrm{C}$, espectro de correlação heteronuclear direta ${ }^{1} \mathrm{H}^{-13} \mathrm{C}$; HMQC, espectro de correlação heteronuclear direta ${ }^{1} \mathrm{H}_{-}{ }^{13} \mathrm{C}$ com sonda inversa; HMBC, espectro de correlação heteronuclear à longa distância ${ }^{1} \mathrm{H}-{ }^{13} \mathrm{C}$ com sonda inversa; HPLC, cromatografia líquida de alto desempenho; FABMS, espectrometria de massas por bombardeamento rápido de átomos; EIMS, espectrometria de massas por impacto eletrônico; UV, espectroscopia no ultravioleta; IV, espectroscopia no infravermelho; TOCSY (total correlation spectroscopy), espectroscopia de correlação total ${ }^{1} \mathrm{H}-{ }^{1} \mathrm{H}$.

\section{NOTA ENVIADA APÓS A REVISÃO FINAL}

Recentemente tomamos conhecimento de que Andersen et al. publicaram no primeiro semestre de 1996 uma revisão intitulada "3-Alkylpiperidine Alkaloids Isolated from Marine Sponges in the Order Haplosclerida" (Andersen, R. J., van Soest, R. W. M., and Kong, F., em Alkaloids: Chemical and Biological Perpesctives, S. W. Pelletier ed., Pergamon Press, 1996, vol. 10, p. 301-355), na qual discutem de maneira aprofundada e definitiva a distribuição de alcalóides 3alquilpiperidínicos, incluíndo 3-alquilpiridínicos, em esponjas marinhas de Ordem Haplosclerida. Os autores deste trabalho propõem uma rota de biossíntese para alcalóides 3-alquilpiridínicos idêntica àquela por nós proposta nos esquemas 14, $15 \mathrm{e}$ 16. Gostaríamos aqui de expressar nossa mais profunda consternação por não termos tomado conhecimento prévio do trabalho destes autores. 


\section{AGRADECIMENTOS}

Os autores agradecem à FAPESP (proc. no 94/0179-8) pelo auxílio concedido para a realização do isolamento de substâncias biologicamente ativas de esponjas marinhas, bem como à CAPES e ao $\mathrm{CNPq}$ pelas bolsas de pós-graduação e de pesquisa concedidas. Eduardo Hajdu agradece ao Prof. Dr. Rob M.W. van Soest pela discussão de tópicos relacionados à distribuição dos alcalóides alquilpiridínicos em esponjas marinhas.

\section{REFERÊNCIAS}

1. Bergquist, P. R.; Sponges; Hutchinson of London, 1978.

2. Boury-Esnault, N.; Em Chimie Marine pour le Développement, J.M. Kornprobst, Ed.; Série Études et Recherches, Dakar, 1983; p. 124-142.

3. Brusca, R. G. e Brusca, G. J., Invertebrates, Sinauer Associates, Sunderle, MA, 1990, p. 181-210.

4. Barnes, R. D.; Zoologia dos Invertebrados, Livraria Roca Ltda., 4 a edição, Rio de Janeiro; p. 95-118.

5. Reiswig, H. e Mackie, G. O.; Phil. Trans. Royal Soc. London 1983, B301, 419-428.

6. Soest, R. W. M. van; Bijdr. Dierk. 1984, 54, 211.

7. Soest, R. W. M. van; Em New Perspectives in Sponge Biology, K. Rützler, Ed.; Smithsonian Institution Press; Washington D. C., 1990; Proc. 3rd Int. Conf. Biol. Sponges, p. 344-348.

8. Bergquist, P. R.; Em The Origin e Relationships of Lower Invertebrates, S. C. Morris et al., eds.; Oxford University Press, 1985; Syst. Assoc. Spec., vol. 28, p. 14-27.

9. Vacelet, J.; Em The Origin e Relationships of Lower Invertebrates, S. C. Morris et al., eds.; Oxford University Press, 1985; Syst. Assoc. Spec., vol. 28, p. 1-13.

10. May, R. M.; Science 1988, 241, 1441.

11. Hammen, C. S. e Florkin, M.; Em Chemical Zoology, M. Florkin e B. T. Scheer, Eds.; Academic Press; New York, 1968, vol. II, p. 53-64.

12. Bergmann, W. e Burke, D. C.; J. Org. Chem. 1955, 20, 1501.

13. Bergmann, W., Gould, D. H. e Low, E. M.; J. Org. Chem. 1945, 10, 570 .

14. Bergmannn, W. e Feeney, R. J.; J. Am. Chem. Soc. 1950, 72, 2809.

15. Bergmann, W. e Feeney, R. J.; J. Org. Chem. 1951, 16, 981.

16. Kornprobst, J. M. e Samb, A.; New. J. Chem. 1990, 14, 703.

17. Bergquist, P. R. e Wells, R. J.; Em Marine Natural Products: Chemical e Biological Perspectives, P. J. Scheuer, Ed.; Academic Press; New York, 1983; vol. 5, p. $1-50$.

18. Braekman, J. C.; Daloze, D.; Stoller, C. e Van Soest, R. W. M.; Biochem. Syst. Ecol. 1992, 20, 417.

19. Uriz, M. J.; Martin, D. e Rosell, D.; Mar. Biol., 1992, 113, 287.

20. Bergquist, P. R.; New Zeal. J. Zool. 1980, 7, 443.

21. Bakus, G. J. e Green, G.; Science 1974, 185, 951.

22. Green, G.; Mar. Biol. 1977, 40, 207.

23. Albericci, M.; Braekman, J. C.; Daloze, D. e Tursch, B.; Tetrahedron 1982, 38, 1881.

24. Braekman, J. C. e Daloze; Pure Appl. Chem. 1988, 58, 357.

25. Jackson, J. B. C. e Buss, L.; Proc. Natl. Acad. Sci. USA. 1975, 72, 5160

26. Sullivan, B. W. e D. J. Faulkner, Em New Perspectives in Sponge Biology, 3rd Int. Sponge Conf. K. Rutzler, Ed.; Smithsonian Institution Press; Washington D. C. e London, 1985; p. 45-50.

27. Porter, J. W. e Targett, N. M.; Biol. Bull. 1988, 175, 230.
28. Thompson, J. E.; Mar. Biol. 1985, 88, 23.

29. Thompson, J. E.; Walker, R. P. e Faulkner, D. J.; Mar. Biol. 1985, 88, 11

30. Walker, R. P.; Thompson, J. E. e Faulkner, D. J.; Mar. Biol. 1985, 88, 27.

31. Sullivan, B.; Faulkner, D. J. e Weble, L.; Science 1983, $221,1175$.

32. Karuso, P.; Em Bioorganic Marine Chemistry, P. J. Scheuer, Ed.; Springer-Verlag; Berlin, 1987; vol. 1, p. 3160.

33. Walker, R. P.; Thompson, J. E. e Faulkner, D. J.; J. Org. Chem. 1980, 45, 4976.

34. Mebs, D.; J. Chem. Ecol. 1985, 11, 713.

35. Neeman, I.; Fishelson, L.; Kashman, Y.; Groweiss, A.; Lidor, R.; Blasberger, D.; Carmely, S.; Tetrahedron 1985 , $41,1905$.

36. Groweiss, A.; Shmueli, U. e Kashman, Y.; J. Org. Chem. 1983, 48, 3512.

37. Huysecom, J.; Van de Vyver, G.; Braekman, J. C. e Daloze, D.; Em New Perspectives in Sponge Biology, 3rd Int. Sponge Conf., K. Rutzler, Ed.; Smithsonian Institution Press; Washingotn D. C. e London, 1985; p. 115-118.

38. Proksch, P.; Toxicon 1994, 32, 639

39. Minale, L.; Pure Appl. Chem. 1976, 48, 7-23.

40. Minale, L.; Cimino, G. De Stefano, S.; Sodano, G.; Fortchr. Chem. org. Naturst. 1976, 33, 1.

41. Minale, L.; Em Marine Natural Products: Chemical $e$ Biological Perspectives, P. J. Scheuer, Ed.; Academic Press, New York, 1978, vol. 1, p. 175-240.

42. Bergquist, P. R.; Em Biologie des Spongiaires, Coll. Int. C. N. R. S., C. Lévi e N. Boury-Esnault, Eds. 1978, 291, 497.

43. Sarma, A. S.; Daum, T.; Muller, W. E. G.; Secondary Metabolites from Marine Sponges, Ullstein Mosby; Mainz, Germany, 1993.

44. Wilkinson, C. R.; Mar. Biol. 1978, 49, 161.

45. Wilkinson, C. R.; Mar. Biol. 1978, 49, 169.

46. Wilkinson, C. R.; Mar. Biol. 1978, 49, 177.

47. Fusetani, N. e Matsunaga, S.; Chem. Rev. 1993, 93, 1793.

48. Kobayashi, J. e Ishibashi, M.; Chem. Rev. 1993, 93, 1753.

49. Marx, R. F., The History of Underwater Exploration, Dover Publications, Inc.; New York, 1990, p. 8.

50. Halstead, B.; Poisonous e Venomous Marine Animals of the World, The Darwin Press; Princeton, New Jersey, 1988; 2nd ed., p. 89-97.

51. Green, G. e Bakus, G. J.; An. Centro Cienc. del Mar y Limnol. Univ. Autón. México 1975, 2, 61.

52. Green, G.; FAO Fisheries Report 1977, 200, 199.

53. Bergquist, P. R. e Bedford, J. J.; Mar. Biol. 1978, 46, 215.

54. Bakus, G. J. e Thun, M. A.; Em Biologie des Spongiaires, Coll. Int. C. N. R. S., C. Lévi e N. Boury-Esnault, Eds. 1978, 291, 417.

55. Amade, P.; Pesando, D. e Chevolot, L.; Mar. Biol. 1982, $70,223$.

56. Russel, F. E.; Adv. Mar. Biol. 1984, 21, 59.

57. McCaffrey, E. J. e Endeau, R.; Mar. Biol. 1985, 89, 1.

58. Green, G.; Gomez, P. e Bakus, G. J.; Em New Perspectives in Sponge Biology, 3rd Int. Sponge Conf., K. Rutzler, Ed.; Smithsonian Institution Press; Washingotn D. C. e London, 1985.

59. Sevcik, C.; Vaello, M. L.; Rodriguez-Herneez, A. J.; Alvarez-Vazquez, F.; Saavedla, A. J. e Garcia-Rodriguez, A. I., Em Neurotoxins in Neurochemistry, J. O. Dolly, Ed., Ellis Horwood Ltd. e John Wiley e Sons; Chichester, Engle, 1988, p. 205-218.

60. Van de Vyver, G.; Huysecom, J.; Braekman, J. C. e Daloze, D.; Vie Millieu 1990, 46, 285.

61. Muricy, G.; Hajdu, E.; Araujo, F. V. e Hagler, A. N.; Sci. Mar. 1993, 57, 427. 
62. Faulkner, D. J.; Nat. Prod. Rep. 1994, 11, 355, e referências citadas.

63. Kelecom, A.; Mem. Inst. Oswaldo Cruz 1991, 86, 99.

64. Munro, M. H. G.; Blunt, J. W.; Lake, R. J.; Litaudon, M., Battershill, C. N. e Page, M. J., Em Sponges in Time e Space, R. W. M. van Soest, J. C. Braekman e T. M. G. Van Kempen, Eds.; Proc. 4th Int. Porifera Congr., Balkema, Rotterdam, p. 473-484.

65. Schmitz, F. J.; Em Sponges in Time e Space, R. W. M. van Soest, J. C. Braekman e T. M. G. Van Kempen, Eds.; Proc. 4th Int. Porifera Congr., Balkema, Rotterdam, p. 485-496.

66. Ayer, W. A. e Habgood, T. E.; Em The Alkaloids, R. H. F. Manske, Ed.; Academic Press; New York, 1968, vol. XI, 459.

67. Strunz, G. M. e Findlay, J. A.; em The Alkaloids, A. Brossi, Ed.; Academic Press, New York, 1985, vol. 26, 89.

68. Sleeper, H. L. e Fenical, W.; J. Am. Chem. Soc. 1977, 99, 2367.

69. Fenical, W.; Sleeper, H. L.; Paul, V. J. Stallard, M. O. e Sun, H. H.; Pure Appl. Chem. 1979, 51, 1865.

70. Sleeper, H. L.; Paul, V. J. e Fenical, W.; J. Chem. Ecol. 1980, 6, 57.

71. Fenical, W.; Sleeper, H. L.; Paul, V. J.; Stallard, M. O. e Sun, H. H.; Pure Appl. Chem. 1979, 51, 1865.

72. Coval, S. J. e Scheuer, P. J.; J. Org. Chem. 1985, 50, 3024.

73. Schinz, H.; Ruzicka, L.; Geyer, V. e Prelog, V.; Helv. Chim. Acta 1946, 29, 1524.

74. De-Quan, Y. e Das, B. C.; Planta Medica 1983, 49, 183.

75. Biemann, K., Büchi, G. e Walker, B. M.; J. Am. Chem. Soc. 1957, 79, 5558.

76. Southon, I. W. e Bickingham, J.; Dictionary of Alkaloids; Chapman; London, New York, 1989.

77. Schmitz, F. J.; Hollenbeak, K. H. e Campbell, D. C.; J. Org. Chem. 1978, 43, 3916-3922.

78. Schmitz, F. J.; Campbell, D. C.; Hollenbeak, K.; Veerah, D. J.; Ciereszko, L. S.; Stendler, P.; Eckstre, J. D.; van der Helm, D.; Kard, P. e Kulkami, S.; Em Marine Natural Products Chemistry, D. J. Faulkner e W.H. Fenical, Eds.; Nato Conferences Series IV, Plenum Press, New York e London, 1978, p. 293-310.

79. Freitas, J. C.; Malpezzi, E. L. A.; Costa, L. V.; Berlinck, R. G. S.; Almeida, A. M. P.; Ogawa, C. A.; Sanchez, M. A. A. e Hajdu, E.; Abstracts of the 5th Pan American Symposium on Animal, Plant e Microbial Toxins, Frederick, Maryland, EUA, 1995.

80. Berlinck, R. G. S.; Almeida, A. M. P.; Ogawa, C. A.; Sanchez, M. A. A.; Freitas, J. C.; Malpezzi, E. L. A. e Hajdu, E.; $18^{a}$ Reunião Anual da Sociedade Brasileira de Química, Caxambu, MG, 1995.

81. Berlinck, R. G. S.; Ogawa, C. A.; Almeida, A. M. P.; Sanchez, M. A. A.; Malpezzi, E. L. A.; Freitas e J. C.; Hajdu, E.; Comp. Biochem. Physiol., no prelo.

82. Dr. José Carlos de Freitas; comunicação pessoal.

83. Quiñoà, E. e Crews, P.; Tetrahedron Lett. 1987, 28, 2467.

84. Kobayashi, J.; Murayama, T.; Ohizumi, Y.; Sasaki, T. Ohta, T. e Nozoe, S.; Tetrahedron Lett. 1989, 30, 4833.

85. Nakamura, Y.; Kobayashi, Y.; Gilmore, J.; Mascal, M.; Rinehart, K. L. Jr.; Nakamura, H. e Ohizumi, Y.; J. Biol. Chem. 1986, 261, 4139.

86. Carroll, A. R. e Scheuer, P. J.; Tetrahedron 1990, 46, 6637.

87. Matsunaga, S.; Shinoda, K. e Fusetani, N.; Tetrahedron Lett. 1993, 34, 5953.

88. Kobayashi, J.; Murayama, T.; Kosuge, S.; Kea, F., Ishibashi, M.; Kobayashi, H.; Ohizumi, Y.; Ohta, T.; Nozoe, S. e Sasaki, T.; J. Chem. Soc. Perkin Trans. I 1990, 3301.

89. Breitmaier, E. e Voelter, W., Carbon-13 NMR Spectroscopy, VCH Publishers, 3rd edition, Weinheim; 1987, p. 236 e 237.
90. Kobayashi, J.; Zeng, C.; Ishibashi, M.; Shigemori, H.; Sasaki, T. e Mikami, Y.; J. Chem. Soc. Perkin Trans. I 1992, 1291.

91. Sakemi, S.; Totton, L. E. e Sun, H. H.; J. Nat. Prod. 1990, 53, 995.

92. Stierle, D. B. e Faulkner, D. J .; J. Nat. Prod. 1991, 54, 1134.

93. Talpir, R.; Rudi, A.; Ilan, M. e Kashman, Y.; Tetrahedron Lett. 1992, 33, 3033.

94. Fusetani, N.; Asai, N.; Matsunaga, S.; Honda, K. e Yasumuro, K.; Tetrahedron Lett. 1994, 35, 3967.

95. Davies-Coleman, M. T.; Faulkner, D. J.; Dubowchik, G. M.; Roth, G. P.; Polson, C. e Fairchild, C.; J. Org. Chem. 1993, 58, 5925 .

96. Albrizio, S.; Ciminiello, P.; Fattorusso, E.; Magno, S. e Pawlik, J. R.; J. Nat. Prod. 1995, 58, 647.

97. Rao, A. V. R.; Reddy, G. R. e Rao, B. V.; J. Org. Chem. 1991, 56, 4545 .

98. March, J.; Advanced Organic Chemistry: Reactions, Mechanisms e Structure, John Wiley e Sons; N. Y., 4th edition, 1992, 1212.

99. Rao, A. V. R. e Reddy, G. R.; Tetrahedron Lett. 1993, $34,8329$.

100. Bracher, F. e Papke, T.; J. Chem. Soc. Perkin Trans I 1995, 2323.

101. Gil, L.; Gateau-Olesker; A., Wong, Y.-S.; Chernatova, L.; Marazano, C. e Das, B. C.; Tetrahedron Lett. 1995, 36, 2059.

102. Ciminiello, P., Constantino, V., Fattorusso, E., Magno, S., Mangoni, A. e Pansini, M.; J. Nat. Prod. 1994, 57, 705.

103. Albrizio, S., Ciminiello, P., Fattorusso, E., Magno, S. e Pansini, M.; Tetrahedron 1994, 50, 783.

104. Karuso, P.; Hagadone, M. R.; Scheuer, P. J. e Bergquist, P. R.; Em New Perspectives in Sponge Biology, 3rd Int. Sponge Conf., K. Rutzler, Ed.; Smithsonian Institution Press; Washingotn D. C. e London, 1985, p. 55-60.

105. Lee, W. L. e Gilchrist, B. M.; Mar. Biol. 1985, 86, 21.

106. Lee, W. L. e Klontz, S .W.; Em New Perspectives in Sponge Biology, 3rd Int. Sponge Conf., K. Rutzler, Ed.; Smithsonian Institution Press; Washingotn D. C. e London, 1985, p. 61-71.

107. Henning, W.; Phylogenetic Systematics, University of Illinois Press, Urbana, Illinois, 1966.

108. Wiley, E. O.; Phylogenetics: The Theory e Practice of Phylogenetic Systematics, John Wiley \& Sons, New York, 1966.

109. Hajdu, E.; Macroevolutionary Patterns Within the Demosponge Order Poecilosclerida. Phylogeny of the Marine Cosmopolitan Genus Mycale, e an Integrated Approach to Biogeography of the Seas, Centrale Durkkerijk, University of Amsterdam, 1995.

110. Garson, M. J.; Nat. Prod. Rep. 1989, 6, 143.

111. Baldwin, J. E. e Whitehead, R. C.; Tetrahedron Lett. 1992 , 33, 2059.

112. Baldwin, J. E.; Claridge, T. D. W.; Heupel, F. A. e Whitehead, R. C.; Tetrahedron Lett. 1994, 35, 7829.

113. Sakai, R.; Higa, T.; Jefford, C. W. e Bernardinelli, G.; $J$. Am. Chem. Soc. 1986, 108, 6404.

114. Nakamura, H.; Deng, S.; Kobayashi, J.; Ohizumi, Y.; Tomotake, Y.; Matsuzaki, T. e Hirata, Y.; Tetrahedron Lett. 1987, 28, 621.

115. Ichiba, T.; Corgiat, J. M.; Scheuer, P. e Kelly-Borges, M.; J. Nat. Prod. 1994, 57, 168.

116. Sakai, R.; Kohmoto, S.; Higa, T.; Jefford, C. W. e Bernardinelli, G.; Tetrahedron Lett. 1987, 28, 5493.

117. Ichiba, T.; Sakai, R.; Kohmoto, S.; Saucy, G. e Higa, T.; Tetrahedron Lett. 1988, 29, 3083.

118. Cimino, G.; Spinella, A. e Trivellone, E.; Tetrahedron Lett. 1989, 30, 133. 
119. Cimino, G.; Puliti, R.; Scognamiglio, G.; Mattia, C. A. e Mazzarella, L.; Pure Appl. Chem. 1989, 61, 535.

120. Cimino, G., De Stefano, S.; Scognamiglio, G.; Sodano, G.; Trivellone, E.; Bull. Soc. Chim. Belg. 1986, 95, 783.

121. Cimino, G.; Mattia, C. A.; Mazzarella, L.; Puliti, R.; Scognamiglio, G.; Spinella e Trivellone, E.; Tetrahedron 1989, 45, 3863 .

122. Kondo, K.; Shigemori, H.; Kikuchi, Y.; Ishibashi, M.; Sasaki, T. e Kobayashi, J.; J. Org. Chem. 1992, 57, 2480.

123. Tsuda, M.; Kawasaki, N. e Kobayashi, J.; Tetrahedron Lett. 1994, 35, 4387.

124. Kobayashi, J.; Tsuda, M.; Kawasaki, N.; Matsumoto, K. e Adachi; Tetrahedron Lett. 1994, 25, 4383.

125. Tsuda, M.; Kawasaki, N.; Kobayashi, J.; Tetrahedron 1994, 50, 7957.

126. Fusetani, N.; Yasumuro, K.; Matsunaga, S. e Hirota, H.; Tetrahedron Lett. 1989, 30, 6891.

127. Braekman, J. C.; Daloze, D.; Macedo de Abreu, P.; Piccinni-Leopardi, C., Germain, G. e Van Meersche, M.; Tetrahedron Lett. 1982, 23, 4277.

128. Braekman, J. C.; Daloze, D.; Defay, N. e Zimmermann, D.; Bull. Soc. Chim. Belg. 1984, 93, 941.

129. Nakagawa, M. e Endo, M.; Tanaka, N. e Gen-Pei, L.; Tetrahedron Lett. 1984, 25, 3227.

130. Baker, B. J.; Scheuer, P. J. e Shoolery, J. N.; J. Am. Chem. Soc. 1988, 110, 965.

131. Fahy, E.; Molinski, T. F.; Harper, M. K.; Sullivan, B. W.; Faulkner, D. J.; Parkanyi, L. e Clardy, J.; Tetrahedron Lett. 1988, 29, 3427.
132. Rodríguez, J.; Peters, B. M.; Kurz, L.; Schatzman, R. C.; McCarley, D.; Lou, L. e Crews, P.; J. Am. Chem. Soc. 1993, 115, 10436

133. Rodríguez, J. e Crews, P.; Tetrahedron Lett. 1994, 35, 4719.

134. Kong, F.; Andersen, R. J. e Allen, T. M.; Tetrahedron 1994, 50, 6137.

135. Kong, F.; Andersen, R. J. e Allen, T. M.; Tetrahedron Lett. 1994, 35, 1643.

136. Kong, F.; Andersen, R. J. e Allen, T. M.; J. Am. Chem. Soc. 1994, 116, 6007.

137. Jaspars, M., Pasupathy, V. e Crews, P.; J. Org. Chem. 1994, 59, 3253

138. Crews, P.; Cheng, X. C.; Adamczeski, M.; Rodríguez, J.; Jaspars, M.; Schmitz, F. J.; Traeger, S. C. e Pordesimo, E. O.; Tetrahedron 1994, 50, 13567.

139. Ohtani, I. I.; Ichiba, T.; Isobe, M.; Kelly-Borges, M. e Scheuer, P. J., J. Am. Chem. Soc. 1995, 117, 10743.

140. Tsuda, M.; Kawasaki, N. e Kobayashi, J.; Tetrahedron Lett. 1994, 35, 4387.

141. Kobayashi, J.; Tsuda, M.; Kawasaki, N.; Matsumoto e Adachi, T.; Tetrahedron Lett. 1994, 35, 4383.

142. Prof. Rob van Soest, comunicação pessoal.

143. Soest, R .W. M. van; Stud. Fauna Curaçao Caribb. Isl. 1980, 62,1 .

144. Hajdu, E.; Weerdt, W. H. e Soest, R. W. M. van; em Sponges in Time e Space (van Soest, R. W. M., van Kempen, T. M. G. e Braekman, J.-C., eds., Proc. IV Int. Porifera Congr., Balkema, Rotterdam, 1994, p. 141-150. 